\title{
Potent KCNQ2/3-Specific Channel Activator Suppresses In Vivo Epileptic Activity and Prevents the Development of Tinnitus
}

\author{
Bopanna I. Kalappa, ${ }^{1 \star}$ Heun Soh, ${ }^{2 \star}$ Kevin M. Duignan, ${ }^{2}$ Takeru Furuya, ${ }^{3}$ Scott Edwards, ${ }^{3}$ Anastasios V. Tzingounis, ${ }^{2}$ \\ and Thanos Tzounopoulos ${ }^{1}$ \\ ${ }^{1}$ Department of Otolaryngology and Neurobiology, University of Pittsburgh, Pittsburgh, Pennsylvania 15261, 2Department of Physiology and Neurobiology, \\ University of Connecticut, Storrs, Connecticut 06269, and ${ }^{3}$ SciFluor Life Sciences, Inc., Cambridge, Massachusetts 02139
}

\begin{abstract}
Voltage-gated Kv7 (KCNQ) channels are voltage-dependent potassium channels that are activated at resting membrane potentials and therefore provide a powerful brake on neuronal excitability. Genetic or experience-dependent reduction of KCNQ2/3 channel activity is linked with disorders that are characterized by neuronal hyperexcitability, such as epilepsy and tinnitus. Retigabine, a small molecule that activates KCNQ2-5 channels by shifting their voltage-dependent opening to more negative voltages, is an US Food and Drug Administration (FDA) approved anti-epileptic drug. However, recently identified side effects have limited its clinical use. As a result, the development of improved KCNQ2/3 channel activators is crucial for the treatment of hyperexcitability-related disorders. By incorporating a fluorine substituent in the 3-position of the tri-aminophenyl ring of retigabine, we synthesized a small-molecule activator (SF0034) with novel properties. Heterologous expression of KCNQ2/3 channels in HEK293T cells showed that SF0034 was five times more potent than retigabine at shifting the voltage dependence of KCNQ2/3 channels to more negative voltages. Moreover, unlike retigabine, SF0034 did not shift the voltage dependence of either KCNQ4 or KCNQ5 homomeric channels. Conditional deletion of Kcnq2 from cerebral cortical pyramidal neurons showed that SF0034 requires the expression of KCNQ2/3 channels for reducing the excitability of CA1 hippocampal neurons. Behavioral studies demonstrated that SF0034 was a more potent and less toxic anticonvulsant than retigabine in rodents. Furthermore, SF0034 prevented the development of tinnitus in mice. We propose that SF0034 provides, not only a powerful tool for investigating ion channel properties, but, most importantly, it provides a clinical candidate for treating epilepsy and preventing tinnitus.
\end{abstract}

Key words: KCNQ channels; epilepsy; tinnitus

\section{Introduction}

Voltage-gated potassium channels are essential regulators of neuronal excitability (Bean, 2007). Especially, potassium channels that are open at potentials close to the resting membrane potential, such as the M-channel, provide a powerful brake to neuronal

Received Dec. 19, 2014; revised April 4, 2015; accepted April 27, 2015.

Author contributions: B.I.K., S.E., A.V.T., and T.T. designed research; B.I.K., H.S., K.M.D., and T.F. performed research; S.E. contributed unpublished reagents/analytic tools; B.I.K., T.F., S.E., A.V.T., and T.T. analyzed data; B.I.K., S.E., A.V.T., and T.T. wrote the paper.

This work was supported by the Department of Defense (Peer Reviewed Medical Research Program Grant PR093405 to T.T.), the Joint Warfighter Medical Research Program (Grant W81XWH-14-1-0117 to T.T.), and the National Institutes of Health (Grant NS073981 to A.V.T.). We thank the National Institute of Neurological Disorders and Stroke-National Institutes of Health anticonvulsant screening program at the University of Utah for performing the anticonvulsant and toxicity studies; Adam Whiteley and Inga Kristaponyte for helping with experiments assessing the behavioral evidence of tinnitus; and Cindy Ling for help in making the figures.

The authors declare no competing financial interests.

*B.I.K. and H.S. contributed equally to this work.

Correspondence should be addressed to either of the following: Thanos Tzounopoulos, Department of Otolaryngology and Neurobiology, Bio-Medical Science Tower 3, Room 3, 3501 Fifth Ave., 10021 BST 3, University of Pittsburgh, Pittsburgh, PA 15261, E-mail: thanos@pitt.edu; or Anastasios V. Tzingounis, Department of Physiology and Neurobiology, 75 North Eagleville Road, University of Connecticut, Storrs, CT 06269, E-mail: anastasios.tzingounis@uconn.edu.

DOI:10.1523/JNEUROSCI.5176-14.2015

Copyright $\odot 2015$ the authors $\quad 0270-6474 / 15 / 358829-14 \$ 15.00 / 0$ excitability. In 1980, Brown and Adams discovered a slowly activating voltage-gated potassium current that was blocked by muscarinic G-protein-coupled receptors in sympathetic neurons, which they named the M-current. The M-current has now been described throughout the central and the peripheral nervous system. In 1998, the channel subunits that underlie the M-current were identified as members of the voltage-gated Kv7 (KCNQ) potassium channel family (Jentsch, 2000). The KCNQ family comprises five members (KCNQ1-5), with KCNQ2/3 heteromers underlying the classical M-current (Wang et al., 1998, but see Wickenden et al., 2001 and Schroeder et al., 2000). The unique importance of KCNQ2/3 channels in maintaining normal levels of excitability is illustrated by the finding that genetic or experience-dependent reductions in KCNQ2/3 channel activity are linked to brain disorders associated with neuronal hyperexcitability, such as epilepsy and tinnitus (Singh et al., 1998; Singh et al., 2003; Li et al., 2013).

Further highlighting the significance of KCNQ channels in controlling neuronal excitability, retigabine, which is an activator of KCNQ2-5 channels, has recently been approved by the FDA as an add-on for the treatment for certain forms of epilepsy (Tatulian et al., 2001; Gunthorpe et al., 2012). Retiga- 
bine exerts its effect by shifting the voltage dependence of KCNQ channels to more hyperpolarized potentials (Tatulian et al., 2001) and therefore increases KCNQ2-5 channel activity both at resting membrane potentials and after a train of action potentials. Such increased KCNQ channel activity prevents excessive firing that is typically associated with seizures, as well as increased spontaneous firing that can trigger tinnitus (Gunthorpe et al., 2012; Li et al., 2013).

Despite its beneficial effects, retigabine causes adverse retinal abnormalities, skin discoloration, as well as urinary retention (Jankovic and Ilickovic, 2013). As a result, these unwanted effects have limited its clinical use. The current hypothesis is that some of the reported adverse effects are due to the poor selectivity of retigabine among KCNQ2-5 channels. For example, KCNQ4 and KCNQ5 channels, which usually do not participate in the M-current-mediated epileptic pathology, are expressed in smooth muscle and are important for regulating contractility. In particular, enhancement of their activity leads to membrane hyperpolarization and resultant reduction in contractile response (Jentsch, 2000; Greenwood and Ohya, 2009). Therefore, nonspecific opening of KCNQ4 and KCNQ5 channels by retigabine leads to unwanted peripheral side effects. Consequently, the need for discovering subtype-specific molecules that are more selective for the KCNQ2/3 channel is crucial for the treatment of hyperexcitability-related disorders.

In this study, by introducing a fluorine atom to retigabine, we synthesized a new chemical entity (SF0034). Next, we evaluated the potency and selectivity of SF0034 for KCNQ channels with in vitro recordings in heterologous systems expressing different KCNQ subunits, in brain slices containing CA1 neurons from wild-type (WT) mice or mice with conditional deletion of Kcnq2 from cerebral cortical pyramidal neurons, and in brain slices from WT mice containing dorsal cochlear nucleus principal neurons (fusiform cells). We then extended this analysis by evaluating the therapeutic potential of SF0034 in animal models of seizures and tinnitus.

\section{Materials and Methods}

\section{SF0034 synthesis}

Step 1: Synthesis of 2-fluoro-N1-(4-fluorobenzyl)-4-nitrobenzene-1,3diamine. To a stirred suspension of commercially available 2,3-difluoro6-nitroaniline (see Fig. 1B, compound 1) (14 g, $80 \mathrm{mmol}, 1.0$ equiv), in dry DMSO (140 ml), 4-fluorobenzylamine (see Fig. 1B, compound 2) was added ( $15 \mathrm{~g}, 120 \mathrm{mmol}, 1.5$ equiv), followed by triethylamine $\left(\mathrm{Et}_{3} \mathrm{~N}\right)$ (28 ml, $193 \mathrm{mmol}, 2.4$ equiv) and molecular iodine $\left(\mathrm{I}_{2}\right)$ (catalytic, 15 $\mathrm{mg}$ ). The reaction mixture was heated to $120^{\circ} \mathrm{C}$ and stirred at this temperature for $3 \mathrm{~h}$. After consumption of the starting material by thin-layer chromatography (TLC), the reaction mixture was cooled to room temperature (RT), diluted with water $(500 \mathrm{ml})$, and extracted with ethyl acetate $($ EtOAc; $2 \times 500 \mathrm{ml})$. The separated organic layer was dried over anhydrous $\mathrm{Na}_{2} \mathrm{SO}_{4}$, filtered, and concentrated under reduced pressure to give a crude product, which was purified by silica gel column chromatography $(\mathrm{EtOAc} /$ hexane $=2 / 23)$ to afford compound $3(20 \mathrm{~g}, 90 \%)$ as a yellow solid. For TLC, $20 \%$ EtOAc/hexane $\left(R_{\mathrm{f}}: 0.20\right)$ was used. For proton nuclear magnetic resonance spectroscopy $\left({ }^{1} \mathrm{H}-\mathrm{NMR} ; 400 \mathrm{MHz}\right.$, $\left.\mathrm{CDCl}_{3}\right), \delta 7.87(\mathrm{dd}, J=9.60,1.60 \mathrm{~Hz}, 1 \mathrm{H}), 7.31-7.28(\mathrm{~m}, 2 \mathrm{H}), 7.08-7.03$ $(\mathrm{m}, 2 \mathrm{H}), 6.11-6.03(\mathrm{~m}, 3 \mathrm{H}), 4.82(\mathrm{br} \mathrm{s}, 1 \mathrm{H}), 4.44(\mathrm{~d}, J=5.2 \mathrm{~Hz}, 2 \mathrm{H})$.

Step 2: Synthesis of ethyl (2-amino-3-fluoro-4-((4-fluorobenzyl)amino)phenyl)carbamate. To a stirred solution of compound 3 (see Fig. $1 B ; 20 \mathrm{~g}, 72 \mathrm{mmol}, 1.0$ equiv) in methanol ( $200 \mathrm{ml})$, zinc powder ( $\mathrm{Zn})(23$ g, $358 \mathrm{mmol}, 5.0$ equiv) was added, followed by dropwise addition of ammonium chloride solution $\left(\mathrm{NH}_{4} \mathrm{Cl}\right)(19 \mathrm{~g}, 358 \mathrm{mmol}$, 5.0 equiv) in $\mathrm{H}_{2} \mathrm{O}(70 \mathrm{ml})$. After being stirred at RT for $3 \mathrm{~h}$, diisopropylethylamine (DIPEA/i-Pr ${ }_{2} \mathrm{NEt}$ ) (14 ml, $86 \mathrm{mmol}, 1.2$ equiv) and ethyl chloroformate $\left(\mathrm{ClCO}_{2} \mathrm{Et}\right)(7.7 \mathrm{~g}, 72 \mathrm{mmol}, 1.0$ equiv) were added to the reaction mixture at $10^{\circ} \mathrm{C}$ and the stirring was continued for another $2 \mathrm{~h}$ at RT. After consumption of the starting material (by TLC), the reaction mixture was diluted with water $(480 \mathrm{ml})$ and stirred for $1 \mathrm{~h}$ to give a solid. The obtained solid was filtered, dissolved in EtOAc $(300 \mathrm{ml})$, and further filtered to remove the undissolved solid. The filtrate was evaporated and recrystallized using hexane to afford brown solid, which was further purified by column chromatography to afford SF0034 (13 g, 56\%) as a colorless solid. For TLC, 50\% EtOAc/Hexane $\left(R_{\mathrm{f}}: 0.20\right)$ was used. For ${ }^{1} \mathrm{H}-\mathrm{NMR}\left(500 \mathrm{MHz}, \mathrm{CDCl}_{3}\right), \delta 7.31(\mathrm{dd}, J=8.2 \mathrm{~Hz}, 6.8 \mathrm{~Hz}, 2 \mathrm{H}), 7.02$ $(\mathrm{dd}, J=6.8 \mathrm{~Hz}, 6.8 \mathrm{~Hz}, 2 \mathrm{H}), 6.75(\mathrm{~d}, J=6.8 \mathrm{~Hz}, 1 \mathrm{H}), 6.07(\mathrm{dd}, J=6.8 \mathrm{~Hz}$, $6.8 \mathrm{~Hz}, 1 \mathrm{H}), 4.31(\mathrm{~s}, 2 \mathrm{H}), 4.22-4.18(\mathrm{~m}, 3 \mathrm{H}), 3.84(\mathrm{br} \mathrm{s}, 2 \mathrm{H}), 1.29(t, J=$ $5.6 \mathrm{~Hz}, 3 \mathrm{H})$.

\section{Retigabine synthesis}

Retigabine (see Fig. 1A) was synthesized as described in International Patent Application WO2011/101456A2, published August 25, 2011 (Example 5); identity and purity were determined by TLC and ${ }^{1} \mathrm{H}-\mathrm{NMR}$.

\section{Animal handling}

Animal handling and care were in accordance with the Institutional Animal Care and Use committee-approved guidelines and protocols of the University of Pittsburgh (Pittsburgh, PA), University of Connecticut (Storrs, CT), and University of Utah (Salt Lake City, UT).

\section{Electrophysiology}

HEK293T electrophysiology. HEK293T cells were transfected with recombinant DNA (3-5 $\mu \mathrm{g}$ ) using Lipofectamine 2000 (Invitrogen) and recorded $48 \mathrm{~h}$ after transfection. All experiments were performed at RT using a conventional whole-cell patch-clamp technique. To record robust KCNQ5 currents, we cotransfected KCNQ5 with pIRES-dsRedPIPKI $\gamma 90(2 \mu \mathrm{g})$. PIPKI $\gamma 90$ increases KCNQ channel open probability (Li et al., 2005). Recording electrodes were filled with internal solution containing the following (in mM): $132 \mathrm{~K}$-gluconate, $10 \mathrm{KCl}, 4 \mathrm{Mg} \cdot \mathrm{ATP}$, 20 HEPES, and 1 EGTA $\cdot \mathrm{KOH}, \mathrm{pH} 7.2-7.3$, and had resistances of 3-5 $\mathrm{M} \Omega$. The standard bath solution contained the following (in $\mathrm{mM}$ ): 144 $\mathrm{NaCl}, 2.5 \mathrm{KCl}, 2.25 \mathrm{CaCl}_{2}, 1.2 \mathrm{MgCl}_{2}, 10$ HEPES, and $22 \mathrm{D}$-glucose, $\mathrm{pH}$ $7.2-7.3$. Series resistance was compensated by $75 \%$. Osmolarity was adjusted to $300-305 \mathrm{mOsm}$ and $\mathrm{pH}$ to $7.2-7.3$ with $\mathrm{NaOH}$. Voltage pulses were applied at $30 \mathrm{~s}$ intervals from a holding potential of $-85 \mathrm{mV}$ to various test pulses before jumping down to $-70 \mathrm{mV}$, as described in the figure legends. These values are adjusted for the calculated junction potential, which was $-15 \mathrm{mV}$. Data were acquired through a Multiclamp 700B amplifier (Molecular Devices), low-pass filtered at $2 \mathrm{kHz}$, and sampled at $10 \mathrm{kHz}$.

Constructs. The KCNQ2/3, KCNQ3 ${ }^{\mathrm{A} 315 \mathrm{~T}}, \mathrm{KCNQ}^{\mathrm{A} 315 \mathrm{~T} / \mathrm{W} 265 \mathrm{~L}}, \mathrm{KCNQ} 4$, and KCNQ5 constructs used in this study have been described previously (Soh and Tzingounis, 2010). To generate the KCNQ2 ${ }^{\mathrm{W} 236 \mathrm{~L}}$ construct, we used the QuikChange II mutagenesis kit (Stratagene) and verified the mutation by sequencing. The PIPKI $\gamma 90$ plasmid was kindly provided by Dr. Robin Irvine (University of Cambridge, Cambridge, UK).

Conditional Kcnq2 knock-out mice. We generated conditional Kcnq2 knock-out mice by breeding Kcnq2 ${ }^{\mathrm{fl} /+} ; E m \times 1^{\mathrm{cre} /+}$ mice as described previously (Soh et al., 2014). For genotyping Kcnq2 floxed mice, two primers were included in each PCR: Kcnq2 lox forward 5'-GGCCCTAGAT TCTGCCTCTT-3' and Kcnq2 lox reverse 5'-AAGATCTCTGCCCC TTCCAT-3'. The primers amplified a 262-bp fragment from the wildtype (WT) allele and a 350-bp product from the floxed allele.

Hippocampal slice preparation and electrophysiology. Transverse hippocampal slices $(300 \mu \mathrm{m})$ were prepared from postnatal day 13 (P13) to P19 mice. Animals were first anesthetized with isoflurane and then immediately decapitated. The brain was quickly removed and placed in ice-cold cutting solution containing the following (in mM): $26 \mathrm{NaHCO}_{3}$, 210 sucrose, 10 glucose, $2.5 \mathrm{KCl}, 1.25 \mathrm{NaH}_{2} \mathrm{PO}_{4}, 0.5 \mathrm{CaCl}_{2}$, and $7 \mathrm{MgCl}_{2}$. Slices were made using a vibratome (Microm HM 650V; Thermo Scientific). Brain slices were placed in a storage chamber filled with artificial cerebrospinal fluid (ACSF) containing the following (in mM): $119 \mathrm{NaCl}$, $2.5 \mathrm{KCl}, 1.3 \mathrm{MgCl}_{2}, 2.5 \mathrm{CaCl}_{2}, 1 \mathrm{NaH}_{2} \mathrm{PO}_{4}, 26 \mathrm{NaHCO}_{3}$, and 10 glucose, equilibrated with $95 \% \mathrm{O}_{2}$ and $5 \% \mathrm{CO}_{2}$. Slices were maintained at $35^{\circ} \mathrm{C}$ for 30-40 min and then at RT for at least $1 \mathrm{~h}$ before recording. All experiments were performed at RT. While recording, slices were continuously perfused in ACSF that also included $2 \mu \mathrm{M}$ CNQX, $10 \mu \mathrm{M}$ APV, and 
$100 \mu \mathrm{M}$ picrotoxin to block fast excitatory and inhibitory synaptic transmission. Hippocampal pyramidal neurons were visually identified with infrared differential interference contrast optics using a $40 \times$ waterimmersion objective lens on an upright microscope (BX51W; Olympus). Whole-cell recordings were obtained using electrodes pulled from thinwalled borosilicate glass capillaries (World Precision Instruments) with resistances ranging from 3.5 to $6 \mathrm{M} \Omega$ and filled with intracellular solution consisting of the following (in $\mathrm{mM}$ ): 130 potassium methylsulfate, 10 $\mathrm{KCl}, 10 \mathrm{HEPES}, 4 \mathrm{NaCl}, 4 \mathrm{Mg}_{2} \mathrm{ATP}, 0.4 \mathrm{Na}_{4} \mathrm{GTP}$, and 20 myo-inositol. Osmolarity was adjusted to 295-300 mOsm and $\mathrm{pH}$ to $7.25-7.35$ with $\mathrm{KOH}$. All slice recordings were taken from pyramidal neurons located in the CA1 region of the hippocampus with an initial resting membrane potential of $<-55 \mathrm{mV}$; junction potential was not corrected for these experiments. Current responses were collected with a Multiclamp 700B amplifier (Molecular Devices), filtered at $2 \mathrm{kHz}$, and sampled at $10 \mathrm{kHz}$. Data were analyzed offline using Clampfit (Molecular Devices) or Origin (OriginLab). For all slice recordings, the membrane potential was set at $-60 \mathrm{mV}$.

Dorsal cochlear nucleus brain slice preparation and electrophysiology. ICR mice (P20-P28) were first anesthetized with isoflurane and then immediately decapitated. Brains were removed and transferred into ACSF maintained at $35^{\circ} \mathrm{C}$ containing the following (in mM): $130 \mathrm{NaCl}, 3$ $\mathrm{KCl}, 1.2 \mathrm{KH}_{2} \mathrm{PO}_{4}, 2.4 \mathrm{CaCl}_{2} \cdot 2 \mathrm{H}_{2} \mathrm{O}, 1.3 \mathrm{MgSO}_{4}, 20 \mathrm{NaHCO}_{3}, 3 \mathrm{Na}-$ HEPES, and 10 D-glucose, saturated with $95 \% \mathrm{O}_{2} / 5 \% \mathrm{CO}_{2}$ ( $\mathrm{pH} 7.25-$ 7.35). Coronal slices $(210 \mu \mathrm{m})$ of the, left dorsal cochlear nucleus (DCN) were prepared in ACSF at $35^{\circ} \mathrm{C}$ using a Vibratome (VT1200 S; Leica). Slices were incubated for $\sim 60 \mathrm{~min}$ at $35^{\circ} \mathrm{C}$ before electrophysiology experiments were conducted.

For patch-clamp experiments, slices were transferred into the recording chamber and perfused with ACSF at a rate of $1-2 \mathrm{ml} / \mathrm{min}$. Fusiform cells were recorded in the fusiform cell layer of the DCN and were identified on the basis of morphological and electrophysiological criteria described in previous studies (Tzounopoulos et al., 2004). Electrophysiological patch-clamp recordings were made using a MultiClamp-700B amplifier equipped with Digidata-1440A A/D converter (Molecular Devices). Voltage- and current-clamp recordings were conducted using 3-5 $\mathrm{M} \Omega$ recording pipettes filled with potassium-based intracellular solution containing the following (in $\mathrm{mm}$ ): $113 \mathrm{~K}$-gluconate, $4.5 \mathrm{MgCl}_{2} \cdot 6 \mathrm{H}_{2} \mathrm{O}, 14 \mathrm{Tris} \cdot$ phosphocreatine, 9 HEPES, 0.1 EGTA, $4 \mathrm{Na}_{2}$ ATP, 0.3 Tris - GTP, 10 sucrose, pH 7.3, at $300 \mathrm{mOsmol}$. Voltage-clamp ramp experiments were performed in the presence of external $1 \mathrm{~mm} \mathrm{CsCl} 2,200 \mu \mathrm{M} \mathrm{CdCl}_{2}$, and $0.5 \mu \mathrm{M}$ tetrodotoxin to block hyperpolarization-activated cyclic nucleotidegated channels ( $\mathrm{HCN}$, Ih channel), calcium channels, and $\mathrm{Na}^{+}$channels, respectively. In experiments in which $\mathrm{CdCl}_{2}$ was added, a $\mathrm{KH}_{2} \mathrm{PO}_{4}$-free ACSF was used to prevent precipitation. XE991 (10 $\left.\mu \mathrm{M}\right)$ was used to block KCNQ channel currents. SF0034 (10 $\mu \mathrm{M})$ was used for electrophysiological experiments from a stock solution of $20 \mathrm{mM}$, prepared using DMSO. Recordings were conducted at $32-34^{\circ} \mathrm{C}$ using an inline heating system (Warner Instruments). Capacitive currents and series resistance $\left(R_{\mathrm{s}}\right)$ were compensated (60-80\%, bandwidth 15 $\mathrm{kHz}$ ). Series resistance was monitored throughout the experiment using the size and shape of the capacitive transients in response to a 5 $\mathrm{mV}$ depolarization step. Experiments were not included if the series resistance changed $>15 \%$ during the recorded session. A liquid junction potential of $-11 \mathrm{mV}$ was corrected for all voltage-clamp experiments. All experiments were conducted in the presence of excitatory and inhibitory synaptic transmission blockers including $20 \mu \mathrm{M}$ 6,7dinitroquinoxaline-2,3-dione (DNQX), $20 \mu \mathrm{M}$ SR95531, and $0.5 \mu \mathrm{M}$ strychnine.

Data analysis and statistics. XE991-sensitive KCNQ channel currents elicited by slow voltage ramps $(8 \mathrm{mV} / \mathrm{s})$ were converted into conductance $(G, \mathrm{nS})$ using Ohm's law: $G=I /\left(V-V_{\mathrm{r}}\right)$, where $I(\mathrm{pA})$ is the current amplitude, $V(\mathrm{mV})$ is the membrane potential, and $V_{\mathrm{r}}$ is the reversal potential of potassium $(-85.5 \mathrm{mV})$. The Boltzmann function (see below) was used to fit the conductance-voltage curves and to determine the maximal conductance $\left(G_{\max }\right)$ and half-maximal activation voltage $\left(V_{1 / 2}\right)$ of KCNQ currents, where $k$ is the slope factor and $G=G_{\max } /\left[1+e^{\wedge}\left\{-\left(V-V_{1 / 2}\right) / k\right\}\right]$.
To obtain the dependence of the changes in $V_{1 / 2}$ on the concentration of different KCNQ channel activators, we measured the $V_{1 / 2}$ of KCNQ2/3 currents at various concentrations of retigabine and SF0034 $(100 \mathrm{nM}-30 \mu \mathrm{M})$. We then fitted the agonist dependence of the shift of the $V_{1 / 2}$ obtained by different concentrations with a Hill equation, where $\Delta V_{1 / 2}=\Delta V_{1 / 2-\max } *$ [activator $]^{\mathrm{n}} /\left(\right.$ [activator $^{\mathrm{n}}+\mathrm{EC}_{50}{ }^{\mathrm{n}} \cdot \Delta V_{1 / 2}$ is the change in $V_{1 / 2}$ caused by the activator, $\mathrm{EC}_{50}$ is the concentration of the KCNQ channel activator that causes $50 \%$ of the maximal effect in $V_{1 / 2}, n$ is the Hill coefficient, and [activator] is the concentration of retigabine or SF0034. Data analysis and statistical tests were performed using GraphPad Prism version 5, Kaleidograph, and MATLAB version 2011a (The MathWorks). Data are reported as mean \pm SEM.

\section{Tinnitus induction, tinnitus screening, and ABRs}

Noise exposure. The noise exposure paradigm and screening of noiseexposed animals for behavioral evidence of tinnitus was conducted similar to previous studies (Li et al., 2013). ICR mice (P17-P20) including both males and females were used in this study. Animals in the noiseexposed group (test) were anesthetized with $3 \%$ isoflurane in oxygen and were exposed unilaterally (left ear) using a narrow band-pass noise with a $1 \mathrm{kHz}$ bandwidth centered at $16 \mathrm{kHz}$ at $116 \mathrm{~dB}$ sound pressure level (SPL) for $45 \mathrm{~min}$. Noise was presented through a pipette tip, one end of which was attached to the speaker (CF-1; Tucker Davis Technologies) and the other inserted to the left ear canal of the mouse. Anesthesia level during noise exposure was maintained at $1-1.5 \%$ isoflurane. Animals in the sham group (control) were subjected to an identical procedure but without any noise exposure.

Behavior screening for tinnitus and auditory brainstem responses. Gap detection, prepulse inhibition (PPI), and auditory brainstem response (ABR) thresholds were assessed right before and 1 week after sham or noise exposure. For the gap detection paradigm, mice were confined in a custom-made chamber constructed using Lego parts and a small plastic container secured using an elastic band. The housing was then placed on load cell response-sensing platforms (E45-E11; Coulbourn Instruments) residing inside a sound-attenuating chamber (env-022SD; Med Associates). The gap detection paradigm was conducted using a narrow bandpass sound with a $1 \mathrm{kHz}$ bandwidth centered at $10,12,16,20,24$, and 32 $\mathrm{kHz}$ test frequencies presented at $70 \mathrm{~dB}$ SPL through an isodynamic tweeter (RT2H-A; HiVi) positioned in front of the animal. Sound gaps of $50 \mathrm{~ms}$ duration were embedded in the background test frequency $130 \mathrm{~ms}$ before the startle stimulus. The startle response represents the time course of the downward force that the animal applies on the platform in response to startle pulse. Gap detection was evaluated based on the gap startle ratio, which is the ratio of peak-to-peak value of startle waveform in the presence of gap to the values in the absence of gap. For gap detection trials of the same background frequency, gap startle ratios were sorted in an ascending manner. To control for variability of gap startle ratios within a frequency, ratios that showed an increase of $>0.5$ from the preceding value were excluded; the following values were also excluded. If more than five ratios were excluded within a frequency, the gap startle ratio for this frequency was not used. Gap startle ratios were measured right before and 1 week after sham or noise exposure. As described in previous studies ( $\mathrm{Li}$ et al., 2013), noise-exposed mice were considered tinnitus mice if their gap startle ratios were increased by $>0.3$ in at least one of the tested frequencies.

In PPI trials, a $50 \mathrm{~ms}, 70 \mathrm{~dB}$ SPL band-pass sound with $1 \mathrm{kHz}$ bandwidth centered at $10,12,16,20,24$ and $32 \mathrm{kHz}$ was presented $130 \mathrm{~ms}$ before the startle stimulus, in an otherwise quiet background. PPI was evaluated based on the PPI startle ratio, which is the ratio of peak-to-peak value of the startle waveform in the presence of prepulse to the peak-topeak value in the absence of the prepulse (startle only trial).

ABR thresholds were measured after the gap detection and PPI tests. For ABR measurements, mice were anesthetized using 3\% isoflurane in oxygen for induction and $1-1.5 \%$ for maintenance. Anesthetized animals were placed in a sound-attenuating chamber with a subdermal electrode placed at the vertex, the ground electrode placed ventral to the right pinna, and the reference electrode placed ventral to the left pinna. Temperature was maintained at $\sim 37^{\circ} \mathrm{C}$ using a heating pad. Sound stimuli were presented using a pipette tip, one end of which was attached to the 
speaker (CF-1; Tucker Davis Technologies) and the other to the left ear canal of the mouse. ABR thresholds were measured for $1 \mathrm{~ms}$ clicks and 3 ms tone bursts of $10,12,16,20,24$, and $32 \mathrm{kHz}$ presented at a rate of 18.56/s using the System 3 software package from Tucker Davis Technologies. Evoked potentials were averaged 1024 times and filtered using a $300-3000 \mathrm{~Hz}$ band-pass filter.

\section{Behavioral screening for tinnitus with SF0034}

ICR mice (P17-P20), both male and female, were randomly assigned into four groups: noise-exposed treated with SF0034 $(n=17)$, noise-exposed treated with vehicle $(0.5 \%$ methylcellulose, $n=17)$, unexposed (shamexposed) treated with SF0034 (sham + SF0034, $n=10$ ), and unexposed treated with vehicle (sham + methylcellulose, $n=10$ ). SF0034 (SciFluor) was formulated as a suspension in $0.5 \%$ methylcellulose and administered $30 \mathrm{~min}$ after noise or sham exposure, followed by injections twice per day for $5 \mathrm{~d}$ every $12 \mathrm{~h}$ via intraperitoneal (i.p.) injection at a dose of 10 $\mathrm{mg} / \mathrm{kg}$. Vehicle-treated groups were injected with $0.5 \%$ methylcellulose using the same injection schedule as that of SF0034-treated groups. All animals were evaluated for gap detection, PPI, and ABR thresholds right before noise or sham exposure and 24-48 h after the final injection.

\section{Animal models of seizures}

All anticonvulsant and toxicity studies were conducted at the University of Utah in association with the National Institute of Neurological Disorders and Stroke-National Institutes of Health Anticonvulsant Screening Program. Male and female albino CF1 mice (18-25 g; Charles River Laboratories) and male albino Sprague Dawley rats (100-300 g) were used for anticonvulsant activity and toxicity screening studies. Animals were housed in a standard $12 \mathrm{~h}: 12 \mathrm{~h}$ light-dark cycle with ad libitum access to standard laboratory chow (Prolab RMH 3000 laboratory diet) and water. Anticonvulsant tests included maximal electroshock (MES) and corneal-kindled seizure paradigms in mice. Toxicity tests included rotarod toxicity test in mice and positional sense/stance/gait toxicity test in rats.

MES seizure test. In the MES seizure test, we assessed the ability of different doses of the test compound in preventing seizure induced by an electrical stimulus of $0.2 \mathrm{~s}$ in duration $(50 \mathrm{~mA}$ at $60 \mathrm{~Hz})$ delivered through the corneal electrodes primed with a drop of anesthetic/electrolyte solution $(0.5 \%$ tetracaine hydrochloride in $0.9 \%$ saline). Mice were restrained by hand and released immediately after corneal stimulation, which allowed observation of the entire seizure episode. A maximal seizure in a test animal includes four distinct phases that include: Phase I: the hind leg flexor component of the tonic phase; Phase II: the hind leg extensor component of the tonic phase; Phase III: intermittent, wholebody clonus; and Phase IV: muscular relaxation followed by seizure termination (Woodbury and Davenport, 1952; Racine et al., 1972). Test compounds were tested for their ability to abolish the hindlimb tonic extensor component, which indicates the compound's ability to inhibit MES-induced seizure spread. In this study, mice were preadministered intraperitoneally with test compounds and tested at $0.25,0.5,1$, and $4 \mathrm{~h}$ time points for the abolishment of hindlimb tonic extensor component after electrical stimulus (SF0034: 5, 5.8, 6.5, 8, and $10 \mathrm{mg} / \mathrm{kg}$; retigabine: $10,13,15$, and $20 \mathrm{mg} / \mathrm{kg} ; n=8-16$ mice/group).

Corneal-kindled mouse model of partial seizures. In the corneal-kindled seizure model, mice were kindled electrically with a $3 \mathrm{~s}, 8 \mathrm{~mA}, 60 \mathrm{~Hz}$ stimulus delivered through corneal electrodes primed with $0.5 \%$ tetracaine hydrochloride in $0.9 \%$ saline twice daily until five consecutive stage $\mathrm{V}$ seizures were induced. Mice were considered kindled when they displayed at least five consecutive stage $\mathrm{V}$ seizures according to the Racine scale (Racine et al., 1972) including mouth and facial clonus (stage I), Stage I plus head nodding (Stage II), Stage II plus forelimb clonus (Stage III), Stage III plus rearing (Stage IV), and stage IV plus repeated rearing and falling (Stage V) (Racine et al., 1972). At the completion of the kindling acquisition, mice were permitted a $3 \mathrm{~d}$ stimulation-free period before any drug testing. On the day of the experiment, fully kindled mice were preadministered intraperitoneally with increasing doses of the test compounds (SF0034: 1.5, 3, 6, 12, and $30 \mathrm{mg} / \mathrm{kg}$; retigabine: 11,43 , and $83 \mathrm{mg} / \mathrm{kg} ; n=8-16 /$ group) and challenged with the corneal-kindling stimulus of $3 \mathrm{~mA}$ for $3 \mathrm{~s} 15 \mathrm{~min}$. Mice were scored as protected (seizure score $\leq 3$ ) or not protected (seizure score $\geq 4$ ) based on Racine scoring (Racine et al., 1972).

\section{Toxicity assays}

Rotarod toxicity assay. In the rotarod test procedure, a mouse is placed on 1-inch knurled rod that rotates at a speed of $6 \mathrm{rpm}$ (Dunham and Miya, 1957). Typically, at this speed, animals were able to maintain equilibrium for long periods of time. The concentration of retigabine or SF0034 that causes mice to fall off the rotating rod 3 times during a $1 \mathrm{~min}$ period is considered toxic. Increasing doses of the test compounds were administered intraperitoneally (SF0034: 10, 20, 50, and $70 \mathrm{mg} / \mathrm{kg}$; retigabine: 15 , $20,30,50,60$, and $70 \mathrm{mg} / \mathrm{kg} ; n=8-16 /$ group).

Positional sense and gait and stance assay. In these assays (Stables and Kupferberg, 1997), animals displaying any of the below described characteristics were considered to have neurological deficits or motor impairment. In the positional sense test, the hind leg of the animal is gently lowered over the edge of a table, to which the animal responds by quickly lifting its leg back to the normal position. Neurological deficit or motor impairment is indicated by the animal's inability to rapidly return its hind leg to the normal position after administration of elevating doses of the test compound. In the gait and stance test, neurological deficit is indicated by a circular or a zigzag gait, ataxia, abnormal spread of legs, abnormal body posture, tremors, hyperactivity, lack of exploratory behavior, somnolence, stupor, catalepsy, or loss of muscle tone. Elevating doses of test compounds were administered orally (SF0034: 75, 125, 175, 185 , and $200 \mathrm{mg} / \mathrm{kg}$; retigabine: $50,75,100$, and $125 \mathrm{mg} / \mathrm{kg} ; n=8-16$ / group).

\section{Determination of median effective dose $\left(E D_{50}\right)$ or median toxic} dose $\left(T D_{50}\right)$

All quantitative in vivo anticonvulsant and toxicity studies were conducted at the time-to-peak effect after intraperitonial injection or oral administration of the compound. Animals were tested with various doses of retigabine or SF0034 until at least three points were established between the limits of $0 \%$ protection or minimal toxicity and $100 \%$ protection or maximal toxicity. The dose of retigabine or SF0034 required to produce the desired endpoint in 50\% of animals [median effective dose $\left(\mathrm{ED}_{50}\right)$ or median toxic dose $\left.\left(\mathrm{TD}_{50}\right)\right]$ was calculated from dose-response curves using Probit analysis (Minitab 17).

\section{Statistics}

For data that were normally distributed (based on the Liliefors test), we conducted Student's $t$ test or one-way or two-way ANOVA. Post hoc analysis for one-way ANOVA was performed with Tukey's least significant test. For non-normally distributed data, we performed the nonparametric Wilcoxon rank-sum test or Kruskal-Wallis test. A binomial test was used for comparing percentages of tinnitus mice in response to different experimental manipulations. The statistical significance in $\mathrm{ED}_{50}$ and $\mathrm{TD}_{50}$ between retigabine and SF0034 were calculated using $95 \%$ or 99\% fiducial confidence intervals determined by Probit analysis.

\section{Results}

\section{Chemical synthesis of SF0034}

Previous studies have shown that retigabine (Fig. $1 A$ ) binds to a hydrophobic pocket between the S5 and S6 domains of KCNQ2-5 channels, thereby stabilizing the open-channel conformation and producing a hyperpolarizing shift in the voltage dependence of these channels (Schenzer et al., 2005; Wuttke et al., 2005; Lange et al., 2009). We hypothesized that retigabine analogs bearing one or two fluorine atoms on the aniline ring would enhance binding to KCNQ2-5 channels. We synthesized a set of fluorinated retigabine analogs with mono- or difluoro- substituents and tested them in a functional cell-based assay for KCNQ2/3 channel activation. When the fluoro group was positioned at the 5-position, the 6-position, or together at the 3- and 5-positions of the tri-aminophenyl ring, no significant changes in potency were observed (data not shown). However, SF0034 (Fig. 1B), a retigabine analog with the fluorogroup at the 3-position of the tri-aminophenyl ring, was unique in 


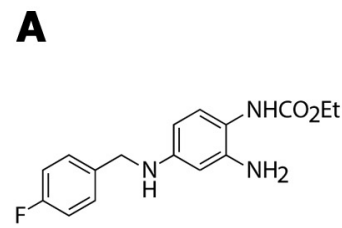

Retigabine
B

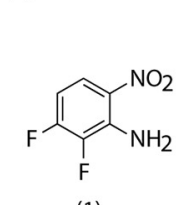

(1)

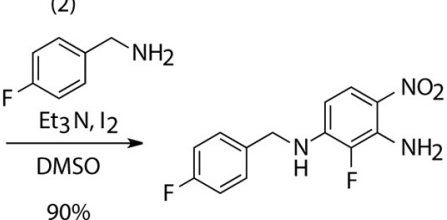

(3)

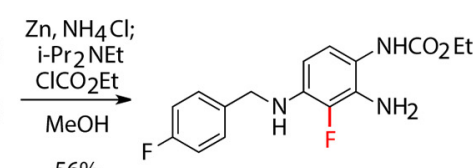

SF0034

Figure 1. SF0034 synthesis. $\boldsymbol{A}$, Structure of retigabine shown for comparison with SF0034. $\boldsymbol{B}$, A regioselective, nucleophilic aromatic substitution of the fluorine para to the nitro group in commercially available 2, 3-difluoro-6-nitroaniline (1) with 4-fluorobenzylamine (2) provided diamino-nitrobenzene (3) in 90\% yield. Reduction of the nitro group in compound (3) to the amino group, followed by selective acylation of the most nucleophilic amino group with ethyl chloroformate, afforded SF0034 as a crystalline solid in $56 \%$ yield.

demonstrating substantially increased potency and selectivity for KCNQ2/3 subunits (see Figs. 2, 3, 4, 5), suggesting that the addition of a fluoro group at the 3-position provides the appropriate steric and electronic modification for increased KCNQ2/3 potency and selectivity.

\section{SF0034 has improved potency and selectivity for KCNQ2/3 subunits}

First, we tested whether SF0034, similarly to retigabine, activates KCNQ2/3 currents. Heterologous expression of KCNQ2/3 channels in HEK293T led to robust slowly activating currents after a $1 \mathrm{~s}$ depolarization at membrane potentials $>-60 \mathrm{mV}$ (Fig. $2 A, C)$. Initially, to evaluate the potency of SF0034 on KCNQ2/3 channels, we measured the effects of $100 \mathrm{nM}, 300 \mathrm{nM}$, and $10 \mu \mathrm{M}$ retigabine and SF0034 on KCNQ2/3 currents. Consistent with previous studies (Tatulian et al., 2001), application of either 100 or $300 \mathrm{nM}$ retigabine did not have any significant effect on KCNQ2/3 currents (Fig. 2A, middle, and B), whereas $10 \mu \mathrm{M}$ retigabine significantly potentiated KCNQ2/3 currents at hyperpolarized membrane potentials without affecting $G_{\max }$ (Fig. $2 A$, right, $B ; G_{\text {max-norm }}$ : control: $0.96 \pm 0.006 ; 10 \mu \mathrm{M}: 1.25 \pm 0.3 ; n=$ $7, p=0.37)$. A Boltzmann fit of the KCNQ2/3 conductancevoltage $(G-V)$ function in the presence of $10 \mu \mathrm{M}$ retigabine revealed a robust shift in the $V_{1 / 2}$ toward more hyperpolarized potentials (Fig. $2 B$, middle and right; $V_{1 / 2}$ : control: $-33 \pm 1.5$ $\mathrm{mV} ; 10 \mu \mathrm{M}:-56 \pm 5 \mathrm{mV}, n=7 ; p<0.01)$.

In contrast to retigabine, application of 100 or $300 \mathrm{~nm} \mathrm{SF0034}$ shifted significantly the $V_{1 / 2}$ of KCNQ2/3 channels toward more hyperpolarized membrane potentials without affecting $G_{\max }$, suggesting that SF0034 is a more potent KCNQ2/3 channel activator than retigabine (Fig. $2 C, D ; V_{1 / 2}$ : control: $-29 \pm 1.7 \mathrm{mV}$; $100 \mathrm{nM}:-35 \pm 1.9 \mathrm{mV}, n=10, p<0.05 ; V_{1 / 2}$ : control: $-30 \pm 2.4$ $\mathrm{mV} ; 300 \mathrm{~nm}:-41 \pm 3.9 \mathrm{mV}, n=5 ; p<0.05$; $G_{\max -\mathrm{norm}}$ : control: $0.95 \pm 0.001 ; 100 \mathrm{~nm}: 1.1 \pm 0.11, n=10, p=0.19$; $G_{\text {max-norm }}$ : control: $0.96 \pm 0.01 ; 300 \mathrm{nM}: 1.2 \pm 0.14, n=5, p=0.15$; $G_{\text {max-norm }}$ : control: $0.96 \pm 0.007 ; 10 \mu \mathrm{M}=1.24 \pm 0.23 ; n=7, p=$ $0.25)$. To quantify the difference in potency between SF0034 and retigabine, we measured the shift in $V_{1 / 2}$ of KCNQ2/3 currents caused by different concentrations of SF0034 and retigabine (100 $\mathrm{nM}$ to $30 \mu \mathrm{M})$ and calculated the $\mathrm{EC}_{50}$ - the concentration of retigabine or SF0034 that produces half-maximal change in the $V_{1 / 2}$ of KCNQ2/3 currents. Retigabine shifted the $V_{1 / 2}$ of KCNQ2/3 currents with an $\mathrm{EC}_{50}$ of $6.5 \mu \mathrm{M}$, whereas SF0034 shifted the $V_{1 / 2}$ of $\mathrm{KCNQ} 2 / 3$ currents with an $\mathrm{EC}_{50}$ of $1.3 \mu \mathrm{M}$, suggesting that SF0034 is approximately five times more potent than retigabine (Fig. 2D, right). This is an important finding showing that the addition of a single fluoride at the 3-position of the tri-aminophenyl ring improves the potency of retigabine in activating KCNQ2/3 channels. Importantly, this result suggests that lower and potentially less toxic concentrations of SF0034 may enhance reduced KCNQ2/3 channel activity associated with hyperactivity-related disorders.

A tryptophan (W) residue in the intracellular end of the S5 helix, W236 for KCNQ2 numbering and W265 for KCNQ3 numbering, is crucial for the gating effects of retigabine on KCNQ channels (Schenzer et al., 2005; Wuttke et al., 2005). To determine whether the gating effect of SF0034 also requires the same $\mathrm{W}$ residue, we examined the effect of SF0034 on KCNQ2 and KCNQ3 subunits that lack W236 or W265, respectively. Because KCNQ3 subunits are the most sensitive subunits to retigabine (Tatulian et al., 2001), we first focused on KCNQ3 channels. We used the KCNQ3 ${ }^{\mathrm{A} 315 \mathrm{~T}}$ mutant channels because they permit robust expression of KCNQ3 currents in HEK293T cells without affecting KCNQ3 gating properties (Hernandez et al., 2009). A concentration of $10 \mu \mathrm{M}$ retigabine shifted the $V_{1 / 2}$ of KCNQ3 ${ }^{\mathrm{A} 315 \mathrm{~T}}$ currents by $\sim 30 \mathrm{mV}$, but substitution of $\mathrm{W} 265$ with leucine (L; KCNQ3 ${ }^{\mathrm{A} 315 \mathrm{~T} / \mathrm{W} 265 \mathrm{~L}}$ ) prevented the gating effect of retigabine (Fig. $3 A ; V_{1 / 2}$ : $\mathrm{KCNQ}^{\mathrm{A} 315 \mathrm{~T}}:-43 \pm 3.6 \mathrm{mV} ; 10 \mu \mathrm{M}$ : $-76 \pm 2.7 \mathrm{mV}, n=5 ; p<0.001 ; \mathrm{KCNQ}^{\mathrm{A} 315 \mathrm{~T} / \mathrm{W} 265 \mathrm{~L}}:-51 \pm 1.8$ $\mathrm{mV} ; 10 \mu \mathrm{M}:-51 \pm 1.9 \mathrm{mV}, n=5 ; p=0.9)$. A concentration of 10 $\mu \mathrm{M}$ SF0034 caused an $\sim 40 \mathrm{mV}$ leftward shift in the $V_{1 / 2}$ of KCNQ3 ${ }^{\mathrm{A} 315 \mathrm{~T}}$ currents, but this shift was abolished in $\mathrm{KCNQ}^{\mathrm{A} 315 \mathrm{~T} / \mathrm{W} 265 \mathrm{~L}}$ currents (Fig. $3 B ; V_{1 / 2}: \mathrm{KCNQ}^{\mathrm{A} 315 \mathrm{~T}}:-45 \pm 2.6$ $\mathrm{mV} ; 10 \mu \mathrm{M}:-87 \pm 2.0 \mathrm{mV}, n=6 ; p<0.001 ; \mathrm{KCNQ}^{\mathrm{A} 315 \mathrm{~T} / \mathrm{W} 265 \mathrm{~L}}$ : $-58 \pm 0.5 \mathrm{mV} ; 10 \mu \mathrm{M}:-58 \pm 1.6 \mathrm{mV}, n=6 ; p=0.8)$. Consistent with our results, SF0034 had a strong gating effect on KCNQ2 currents (Fig. 3C, left); however, this effect was abolished upon substitution of $\mathrm{W}$ with $\mathrm{L}\left(\mathrm{KCNQ} 2^{\mathrm{W} 236 \mathrm{~L}}\right)$, further confirming the necessity of W236 for the gating effect of SF0034 (Fig. 3C, right). Together, these results suggest that, although SF0034 is more potent than retigabine, it also requires W236/W265 for exerting its gating effects on KCNQ2 and KCNQ3 homomeric channels.

Next, we assessed the selectivity of SF0034 in activating different KCNQ subunits. Because retigabine does not activate KCNQ1 channels, but activates KCNQ4 and KCNQ5 channels (Tatulian et al., 2001; Jensen et al., 2005), we investigated the effects of SF0034 on KCNQ4 and KCNQ5 homomeric channels (Fig. 4A-D). We found that SF0034 did not alter the $V_{1 / 2}$ of either KCNQ4 or KCNQ5 channels (Fig. 4B, right; KCNQ4: $V_{1 / 2}$ control $=-17 \pm 6 \mathrm{mV} ; 10 \mu \mathrm{M}=-28 \pm 6 \mathrm{mV} ; n=5, p=$ 0.1 ; Fig. $4 D$, right; KCNQ5: $V_{1 / 2}$ control $=-62 \pm 7.6 \mathrm{mV} ; V_{1 / 2}$ $10 \mu \mathrm{M}=-72 \pm 8 ; n=3, p=0.4)$. Similarly, SF0034 did not increase significantly either KCNQ4 or KCNQ5 $G_{\max }$ (Fig. $4 B$, left; KCNQ4: $G_{\text {max-norm }}$ control $=1.2 \pm 0.08 ; 10 \mu \mathrm{M}=2.6 \pm$ $0.6 ; n=5, p=0.1$; Fig. $4 D$, left; KCNQ5: $G_{\text {max-norm }}$ control: $1.06 \pm 0.004 ; 10 \mu \mathrm{M}=1.1 \pm 0.2 ; n=3, p=0.8)$. The effects of SF0034 on KCNQ4 channels are significantly different from the effects reported previously for retigabine (Tatulian et al., 2001). In agreement with these studies, our experiments showed that retigabine shifted the $V_{1 / 2}$ to hyperpolarized 
A

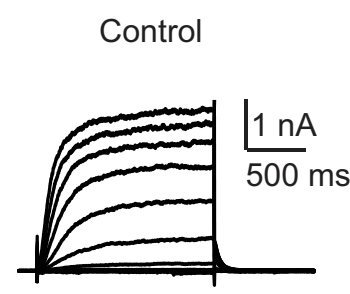

B

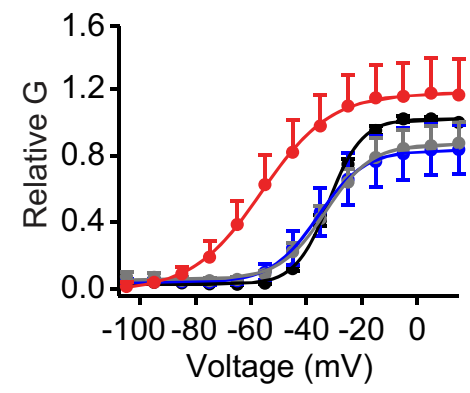

Retigabine (100 nM)
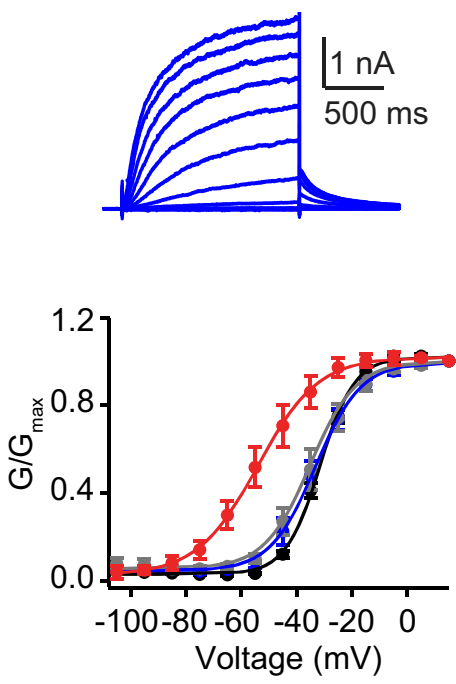

C

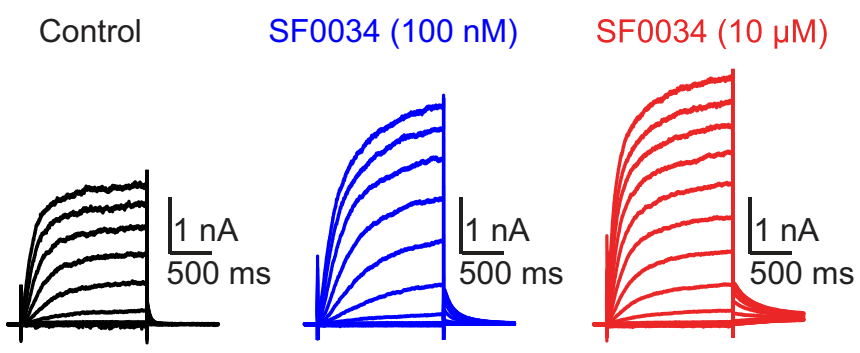

D
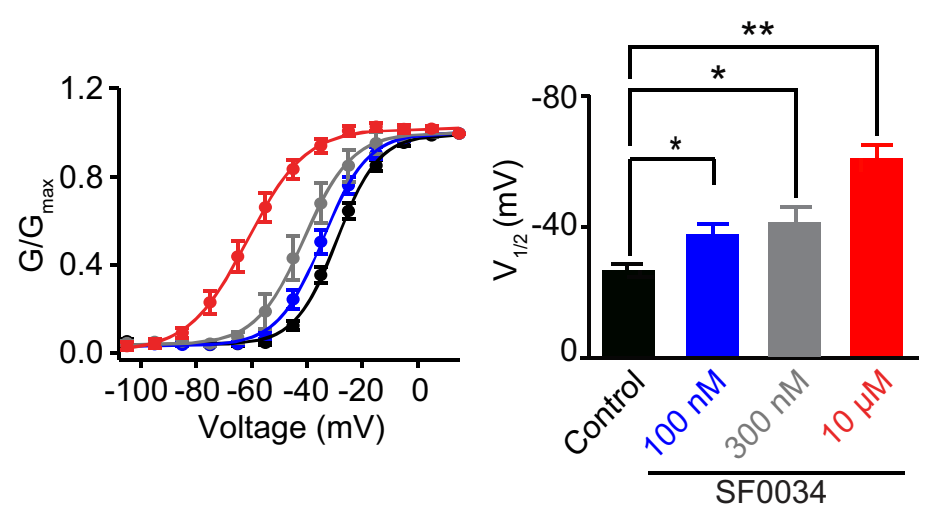

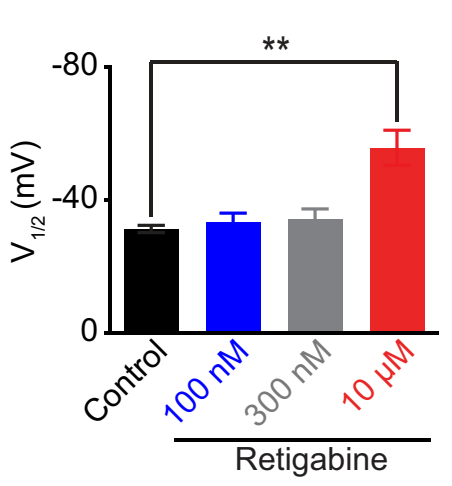

Retigabine $(10 \mu \mathrm{M})$
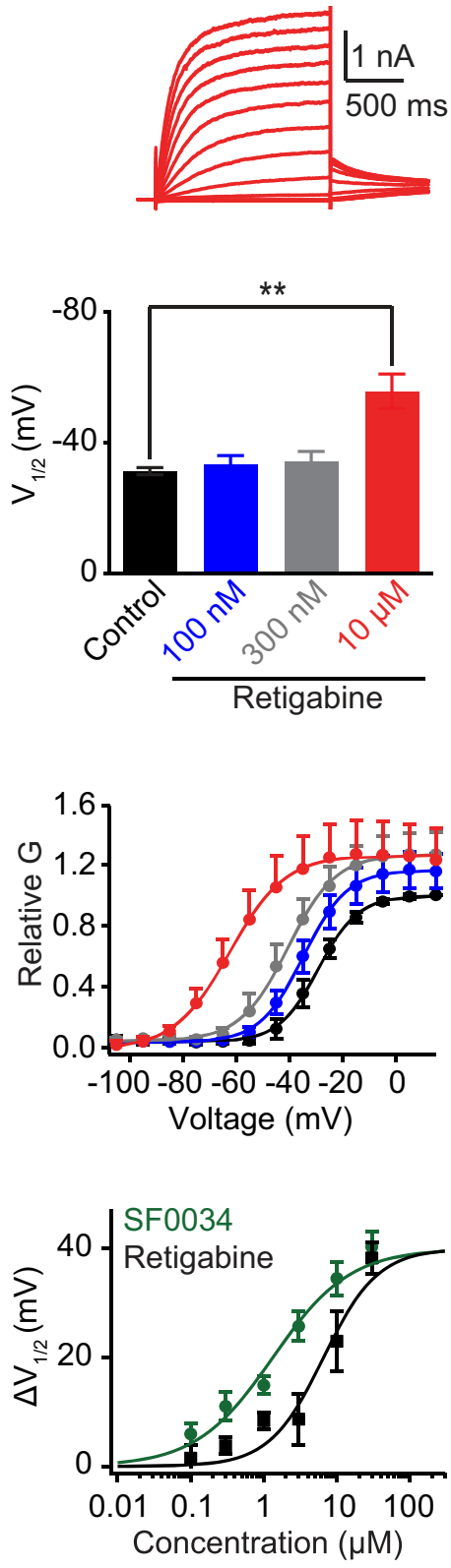

Figure 2. SF0034 is more potent in activating KCNQ2/3 channels than retigabine. KCNQ2/3 currents were measured at various test potentials elicited by a $1 \mathrm{~s}$ depolarization from $-85 \mathrm{mV}$ and were followed by a return step to $-70 \mathrm{mV}$. Test potentials were given at $10 \mathrm{mV}$ increments from -115 to $+15 \mathrm{mV}$. $A, C$, Representative current traces at different membrane potentials from HEK293T cells expressing KCNQ2/3 channels in the presence of increasing concentrations of either retigabine (A) or SF0034 (C). $\boldsymbol{B}$, Left and Middle, Summary of the relative and normalized G-V relationship of KCNQ2/3 channels at control $(n=19), 100 \mathrm{~nm},(n=7), 300 \mathrm{~nm},(n=5)$, and $10 \mu \mathrm{m},(n=7)$ retigabine. Right, Summary of the $V_{1 / 2}$ at different retigabine concentrations (control: $n=19 ; 100 \mathrm{~nm}, n=7 ; 300 \mathrm{~nm}, n=5 ;$ and $10 \mu \mathrm{M}, n=7 ; p<0.05)$. C, Right, Summary of the relative G-V relationship of KCNQ2/3 channels at control $(n=16), 100 \mathrm{~nm}(n=10), 300 \mathrm{~nm}(n=$ 5), and $10 \mu \mathrm{M}(n=7)$ SF0034. D, Left, Summary of the normalized G-V relationship of KCNQ2/3 channels at SF0034 (control: $n=16 ; 100 \mathrm{~nm}, n=10 ; 300 \mathrm{~nm}, n=5 ;$ and $10 \mu \mathrm{m}, n=7$ ). Middle, Summary of the $V_{1 / 2}$ at different SF0034 concentrations (control: $n=16 ; 100 \mathrm{~nm}, n=10 ; 300 \mathrm{~nm}, n=5$; and $10 \mu \mathrm{m}, n=7 ;{ }^{*} p<0.05$; ${ }^{* *} p<0.01$ ). Right, Concentration-response curves of the half-activation shift $\left(\Delta V_{1 / 2}\right)$ for SF0034 $(n=4-10)$ and retigabine $(n=4-9)$. Values are plotted against either retigabine (black) or SF0034 (green) concentration. Data were fitted with a Hill equation with the following parameters: retigabine: $\mathrm{EC}_{50} 6.5 \pm 1.5 \mu \mathrm{M}, \Delta V_{1 / 2-\max }=40 \mathrm{mV}$, slope $=1.1, n=4-9 ; \mathrm{SFO034}: \mathrm{EC}_{50} 1.3 \pm 0.2 \mu \mathrm{m}, \Delta V_{1 / 2-\mathrm{max}}=40 \mathrm{mV}$, slope $=0.8, n=4-9$. Error bars indicate \pm SEM. ${ }^{*} p<0.05 ;{ }^{* *} p<0.01$.

membrane potentials and increased the $G_{\max }$ of KCNQ4 channels (control $V_{1 / 2}=-31 \pm 3 \mathrm{mV} ; 10 \mu \mathrm{M}=-51 \pm 9 \mathrm{mV}, n=$ $4, p<0.01 ;$ control $G_{\text {max-norm }}=0.97 \pm 0.03 ; 10 \mu \mathrm{M}=1.93 \pm$ $0.2 \mathrm{mV}, n=4, p<0.01$, data not shown). Importantly, at potentials near the resting membrane potential, SF0034 did not have any significant effect on either KCNQ4 or KCNQ5 channels. These findings suggest that administration of SF0034 in vivo might not activate KCNQ4/5 channels and may therefore cause less side effects. Together, our results suggest that SF0034 is a specific modulator of a subset of KCNQ channels, notably showing the highest affinity and efficacy for KCNQ2/3 channels. 
$\mathrm{KCNQ3}^{\mathrm{A} 315 \mathrm{~T}}$

A
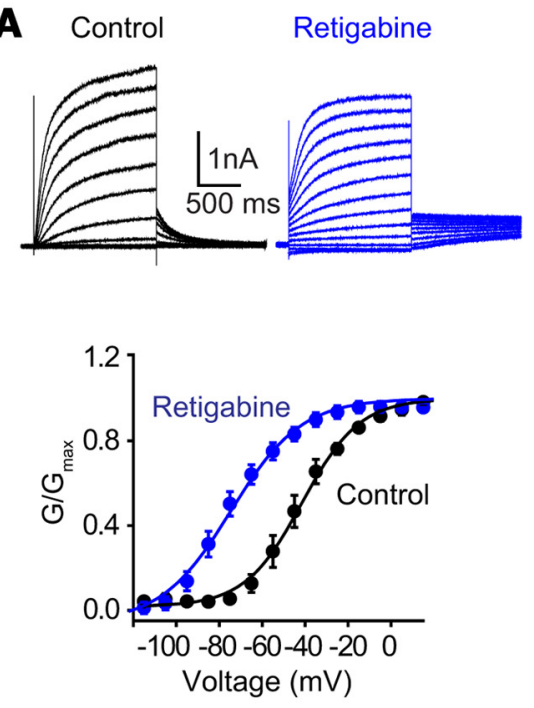

B
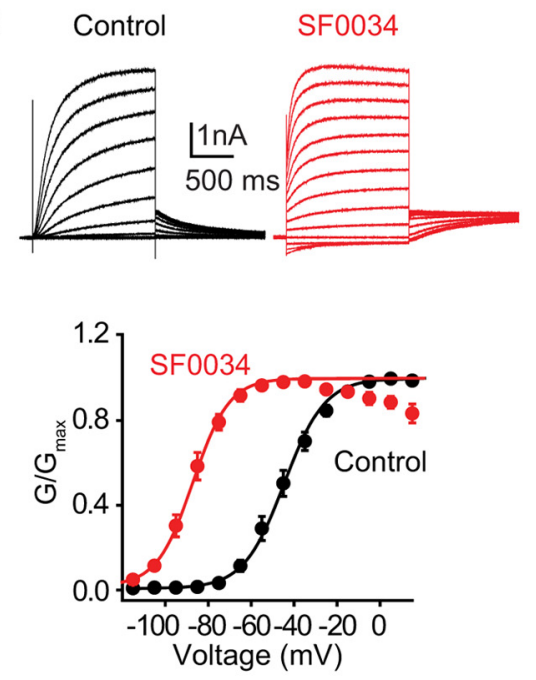

C

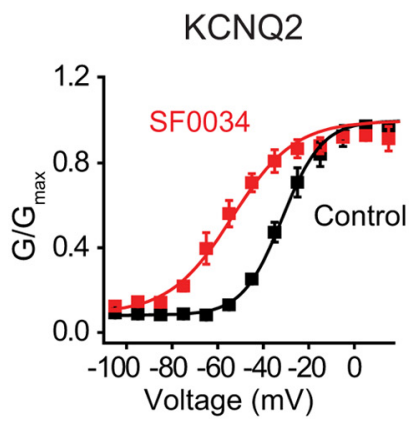

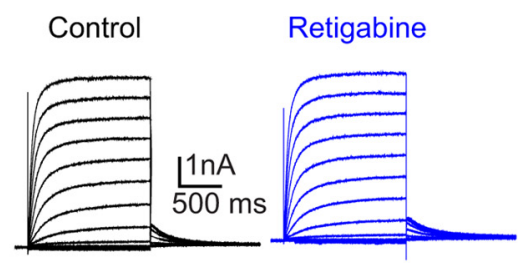
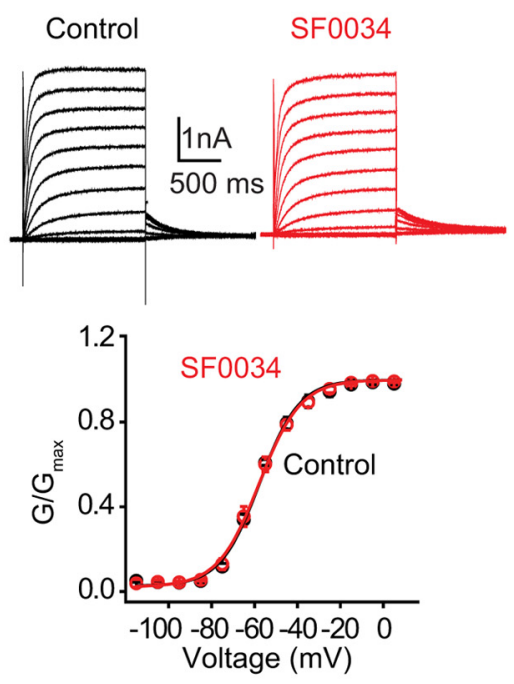

W236L

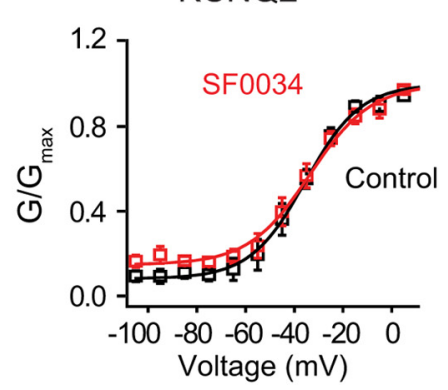

$\mathrm{KCNQ3}^{\mathrm{A} 315 \mathrm{~T} / \mathrm{W} 265 \mathrm{~L}}$

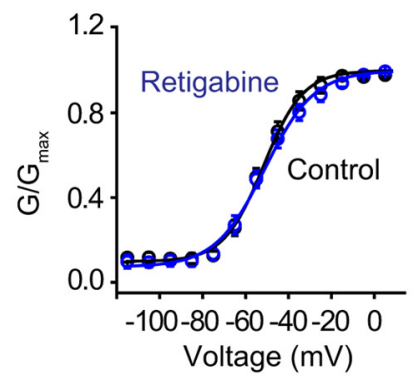

Figure 3. SF0034 requires the presence of W265 or W236 to exert its gating effects on KCNQ3 or KCNQ2 channels, respectively. KCNQ currents were measured at various test potentials elicited by a $1 \mathrm{~s}$ depolarization from $-85 \mathrm{mV}$ and were followed by a return step to $-70 \mathrm{mV}$. Test potentials were given at $10 \mathrm{mV}$ increments from -115 to $+15 \mathrm{mV}$. $\boldsymbol{A}$, Top, Representative current traces recorded at different membrane potentials from HEK293T cells expressing KCNQ3 ${ }^{\text {A315T }}$ (left) or KCNQ3 ${ }^{\text {A315T/W265L }}$ (right) channels in the presence or absence of $10 \mu \mathrm{m}$ retigabine. Bottom, Summary of the normalized $G-V$ relationship of KCNQ3 ${ }^{\mathrm{A} 315 \mathrm{~T}}$ (left, $n=5$ )

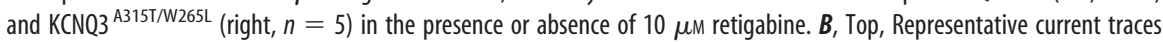
recorded at different membrane potentials from HEK293T cells expressing KCNQ3 ${ }^{\text {A315T }}$ (left) or KCNQ3 ${ }^{\text {A315T/W265L (right) channels }}$ in the presence or absence of $10 \mu \mathrm{m}$ SF0034. Bottom, Summary of the normalized G-V relationship of KCNQ3 ${ }^{\text {A315T }}($ left, $n=6)$ and KCNQ3 ${ }^{\mathrm{A315T} / \mathrm{W} 265 \mathrm{~L}}$ (right, $n=4$ ) in the presence or absence of $10 \mu \mathrm{m}$ SF0034. C, Summary of the normalized G-V relationship of

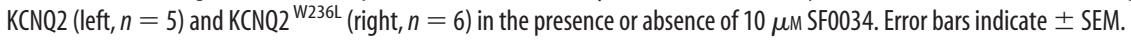

SF0034 activates neuronal KCNQ2/3 channels and controls neuronal excitability

So far, we have examined the effects of SF0034 in heterologous systems. Although heterologous systems are appropriate for evaluating SF0034-subunit-specific effects, they are not optimal for determining the specificity of SF0034 over other conductances that may affect neuronal excitability. To assess the specificity of SF0034 in modulating excitability through KCNQ2/3 modulation, we evaluated the effect of SF0034 in brain slices from mice with conditional deletion of Kcnq2 from cerebral cortical pyramidal neurons (Kcnq2 cKO) (Soh et al., 2014). We opted to use Kcnq2 cKO mice for this test because previous studies showed that conditional Kcnq2 deletion decreased KCNQ2/3 and M-currents dramatically in CA1 pyramidal neurons (Soh et al., 2014). This reduction is due to the loss of both KCNQ2 and KCNQ3 channel surface expression (Soh et al., 2014). Consistent with these findings, we also found that CA1 pyramidal neurons from Kcnq2 cKO mice were hyperexcitable and showed an increased number of action potentials (compare left columns between Fig. $5 A$ and $C$ ).

To determine whether SF0034 reduces neuronal excitability via KCNQ2/3 modulation in CA1 pyramidal neurons, we recorded in the current-clamp mode. Application of a series of $1 \mathrm{~s}$ depolarizing current steps in $25 \mathrm{pA}$ increments resulted in a stepwise increase in the number of evoked action potentials (Fig. 5A,C). Application of $10 \mu \mathrm{M}$ SF0034 in WT CA1 neurons significantly decreased the number of action potentials at all current injections tested (Fig. $5 A, B$; control $_{+250 \mathrm{pA}}$ : $21 \pm 2 \mathrm{AP} ; \mathrm{SF} 0034_{+250 \mathrm{pA}}: 5 \pm 2 \mathrm{AP}, n=6$; $p<0.01)$. In contrast, in Kcnq2 cKO CA1 neurons, the ability of SF0034 to dampen excitability was reduced significantly (Fig. $4 C, D ;$ control $_{+250 \mathrm{pA}}: 30 \pm 2 \mathrm{AP}$; SF0034 ${ }_{+250 \mathrm{pA}}: 28 \pm 3 \mathrm{AP}, n=6 ; p=$ $0.05)$, which is consistent with the notion that the action of SF0034 on excitability is very specific and requires the presence of KCNQ2-containing channels. At subsaturating current injections, SF0034 decreased significantly the number of action potentials in Kcnq2 cKO neurons (WT neurons, control ${ }_{+100 \mathrm{pA}}: 13 \pm 1 \mathrm{AP}$; SF0034 $+100 \mathrm{pA}: 0.7 \pm 0.2 \mathrm{AP}, n=6 ; p<$ 0.0001; Kcnq2-null neurons, control $+100 \mathrm{pA}$ : $17 \pm 2 \mathrm{AP} ; \mathrm{SF} 0034_{+100 \mathrm{pA}}: 13 \pm 2 \mathrm{AP}, n=6$; $p<0.01)$. This effect is likely due to the presence of a small residual KCNQ current in Kcnq2 cKO neurons (Soh et al., 2014) that is likely mediated by KCNQ3 
A KCNQ4 (Control)

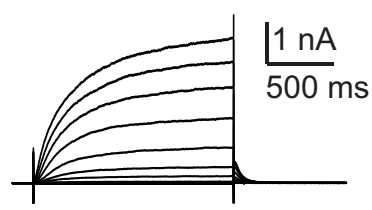

B

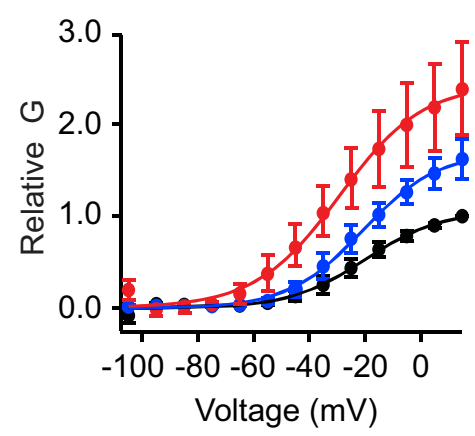

C

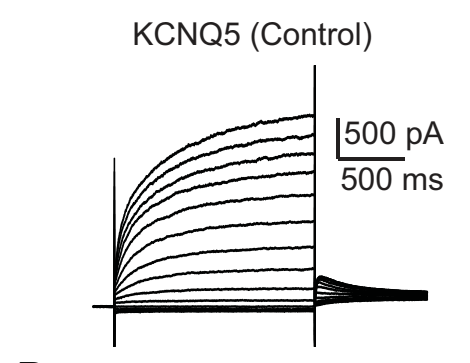

D

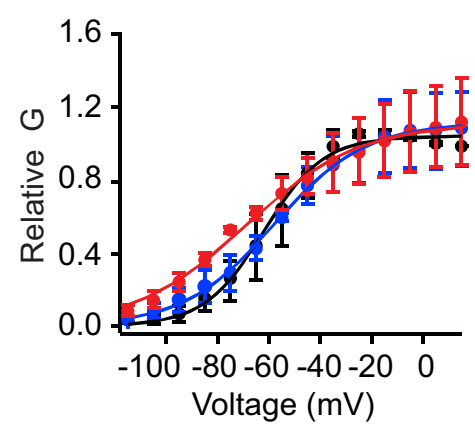

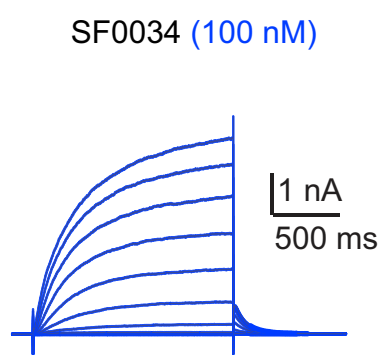
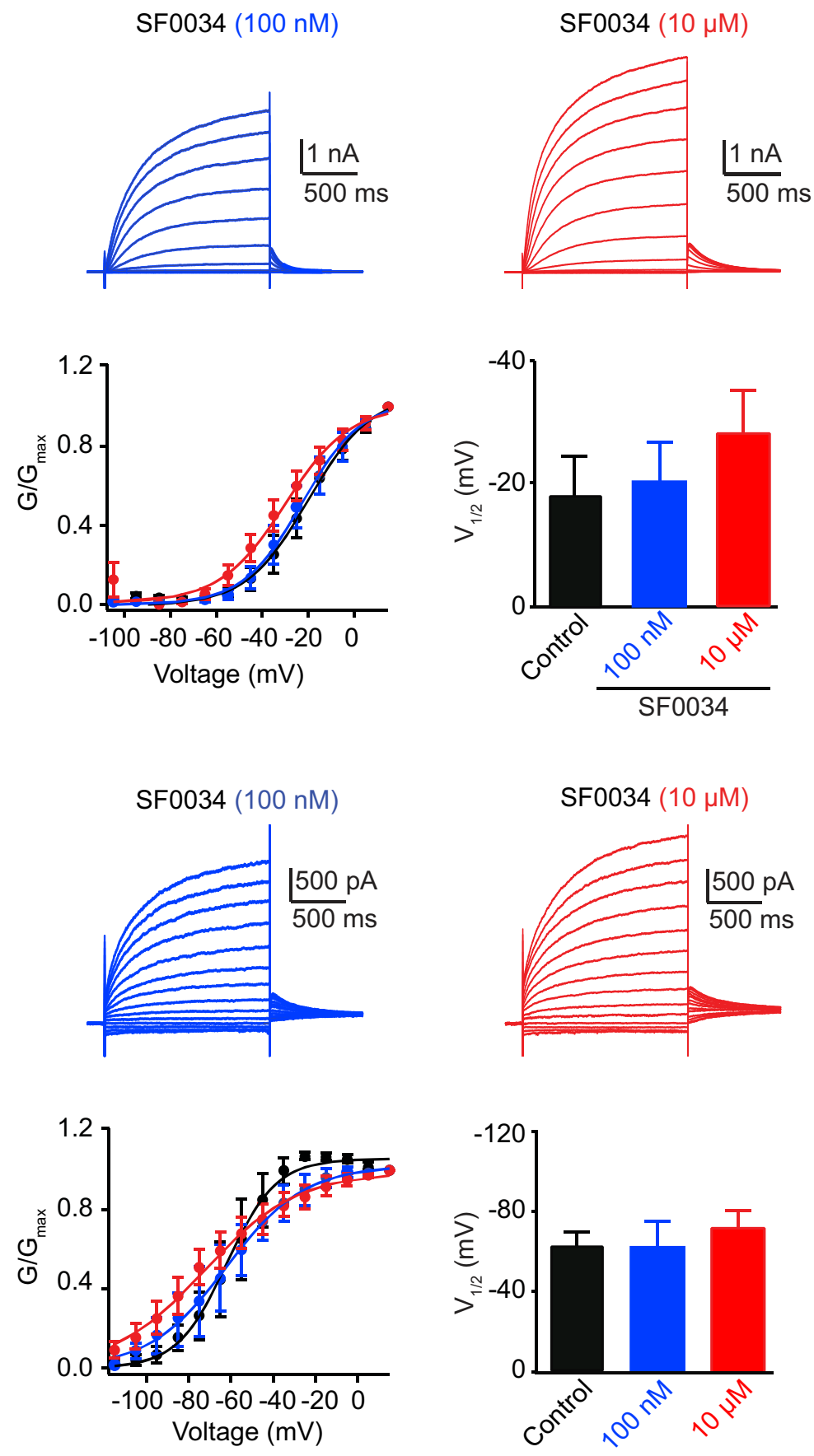

Figure 4. SF0034 has minimal effects on KCNQ4 and KCNQ5 channels. KCNQ currents were measured at various test potentials elicited by a $1 \mathrm{~s}$ depolarization from $-85 \mathrm{mV}$ and were followed by a return step to $-70 \mathrm{mV}$. Test potentials were given at $10 \mathrm{mV}$ increments from -115 to $+15 \mathrm{mV}$. $\boldsymbol{A}$, Representative current traces at different membrane potentials from HEK293T cells expressing KCNQ4 channels in the presence of either $100 \mathrm{~nm}$ or $10 \mu \mathrm{m}$ SF0034. B, Left and Middle, Summary of the relative and normalized G-V relationship of KCNQ4 channels at two different SF0034 concentrations $(100 \mathrm{~nm}, 10 \mu \mathrm{M})$. Right, Summary of the SF0034-induced shift at the $V_{1 / 2}(n=5)$. C, Representative current traces at different membrane potentials from HEK293T cells expressing KCNQ5 channels in the presence of either $100 \mathrm{~nm}$ or $10 \mu \mathrm{m}$ SF0034. D, Left and Middle, Summary of the relative and normalized G-V relationship of KCNQ5 channels at the two different SF0034 concentrations $(100 \mathrm{~nm}, 10 \mu \mathrm{M})$. Right, Summary of the effect of SF0034 at the $V_{1 / 2}(n=3)$. Error bars indicate \pm SEM.

or KCNQ3/5 channels. This conclusion is consistent with previous studies showing that KCNQ2 ablation significantly decreased, but did not eliminate, either KCNQ3 or KCNQ5 protein levels (Soh et al., 2014). Together, our results indicate that SF0034 is a potent and selective KCNQ2/3 channel activator that reduces CA1 neuronal excitability through activation of KCNQ2/3 channels.
Because recent studies have revealed that a reduction in KCNQ2/3 potassium channel activity in the principal DCN neurons (fusiform cells) is essential for tinnitus induction (Li et al., 2013), we also examined the effect of SF0034 on KCNQ currents, which are mediated by KCNQ2/3 subunits (Li et al., 2013), in fusiform cells from DCN brain slices. A slow voltage ramp (8 $\mathrm{mV} / \mathrm{s}$ ) elicited an outward current (Fig. 6A, black trace) that was 
A

WT
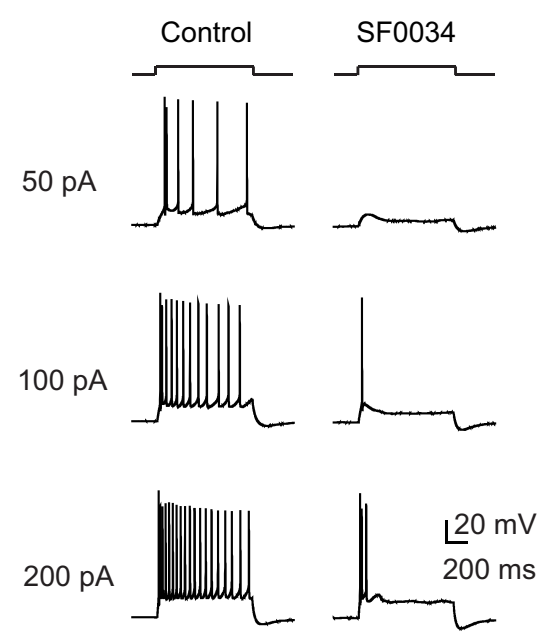

B

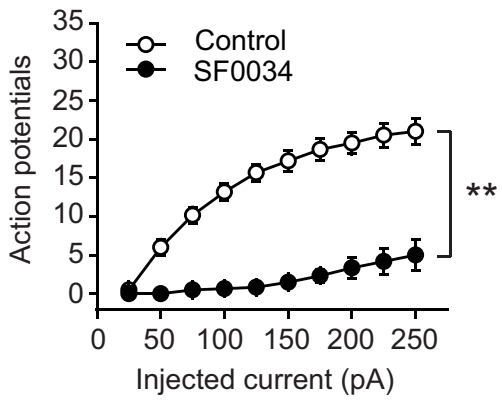

C Kcnq2 cKO
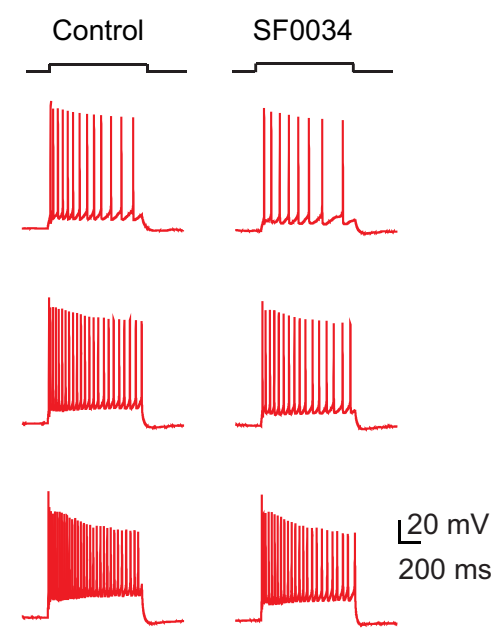

D

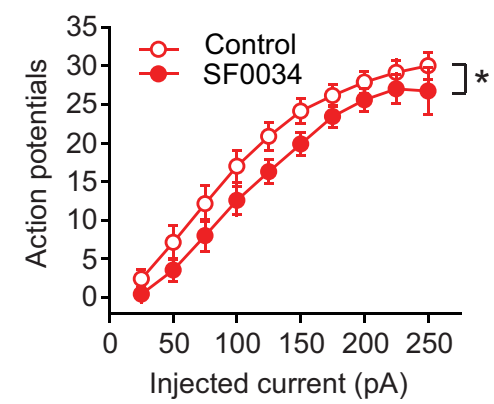

Figure 5. SF0034 requires the presence of KCNQ2/3 channels to dampen neuronal excitability in CA1 pyramidal neurons. $A, C$, Voltage responses to depolarizing current injections ( $1 \mathrm{~s}, 25 \mathrm{pA}$ to $250 \mathrm{pA}$; in $25 \mathrm{pA}$ increments) in CA1 pyramidal neurons from WT $(\boldsymbol{A})$ and $\mathrm{Kcnq2}$ cKO mice $(\boldsymbol{C})$ in the presence (right) or absence (left) of $10 \mu \mathrm{m}$ SF0034. Resting membrane potential was set at $-60 \mathrm{mV} . B, D$, Summary graphs showing the effect of SF0034 on CA1 pyramidal neurons action potential number in CA1 pyramidal neurons from WT (B) and Kcnq2 cK0 mice (D). Error bars indicate \pm SEM. ${ }^{*} p<0.05 ;{ }^{* *} p<0.01$.

potentiated by application of $10 \mu \mathrm{M}$ SF0034 (Fig. 6A, red trace) and partially suppressed by subsequent bath application of $10 \mu \mathrm{M}$ XE991, a selective KCNQ antagonist (Fig. 6A, blue trace). Bath administration of $10 \mu \mathrm{M}$ SF0034 after applying XE991 did not potentiate the XE991-resistant currents (Fig. 6B), suggesting that SF0034 specifically enhances KCNQ2/3 currents. By digitally subtracting the current response after application of XE991 from the control response, we determined the $G-V$ relationship for $\mathrm{KCNQ} 2 / 3$ currents in control (Fig. $6 C$, gray trace) and in the presence of SF0034 (Fig. 6C, black trace). SF0034 significantly reduced the $V_{1 / 2}$ to more hyperpolarizing potentials and enhanced the $G_{\max }$ of KCNQ2/3 currents in fusiform cells (Fig. $6 C-E ; V_{1 / 2}$, control: $-26.6 \pm 1.4 \mathrm{mV}$, SF0034: $-33.2 \pm 1.8 \mathrm{mV}$, $n=6, p<0.01 ; G_{\max }$, control: $63.6 \pm 8.5 \mathrm{nS}$, SF0034: $90.7 \pm 14.2$ $\mathrm{nS}, n=6, p<0.05$ ).

Fusiform cells fire spontaneous action potentials (Leao et al., 2012) and KCNQ2/3 channel activity modulates the spontaneous firing rate of fusiform cells dramatically (Li et al., 2013). Consistent with this finding and our voltage-clamp data on the enhancing effect of SF0034 on KCNQ2/3 currents, $10 \mu \mathrm{M}$ SF0034 abolished spontaneous firing (Fig. $6 F$ ); this inhibition was reversed upon blocking KCNQ2/3 channels with XE991 (Fig. 6F). Together, these results suggest that SF0034 enhances KCNQ2/3 channel activity in fusiform cells and determines the spontaneous firing properties of fusiform cells, further supporting the specificity of SF0034 and its ability to regulate excitability in different neuronal types.

\section{SF0034 exhibits stronger anticonvulsant} activity and is less toxic than retigabine Based on our electrophysiological experiments showing improved potency and selectivity in activating KCNQ2/3 channels, we hypothesized that SF0034 would be more potent in preventing the development of seizures and less toxic compared with retigabine in animal models of seizures and toxicity. To test this hypothesis, we explored the effect of SF0034 with in vivo behavioral studies. In particular, we compared the effects of SF0034 and retigabine in animal models of epilepsy and tinnitus, which are hyperexcitability-related disorders associated with pathologically reduced KCNQ2/3 channel activity.

To compare the potency of SF0034 with the potency of retigabine in preventing epileptic seizures, we determined the $\mathrm{ED}_{50}$, the dose of retigabine or SF0034 required to stop seizures in $50 \%$ of the tested animals, in mouse models of generalized seizures (MES seizure) and partial seizures (corneal-kindled). The MES seizure model is one of the most widely used seizure models that is relevant to human generalized tonic-clonic and myoclonic seizures (White et al., 1995). In the MES test, an electrical stimulus $(50 \mathrm{~mA}$ for $0.2 \mathrm{~s}$ ) is delivered through corneal electrodes and the dose-dependent ability of anticonvulsant drugs to abolish hindlimb tonic extensor is evaluated. In the MES model, SF0034 was significantly more potent than retigabine in abolishing the hindlimb extensor component (Fig. 7A; SF0034, $\mathrm{ED}_{50}: 6.18 \pm 2.12 \mathrm{mg} / \mathrm{kg}$; retigabine, $\mathrm{ED}_{50}: 14.25 \pm 3.25 \mathrm{mg} / \mathrm{kg}, p<0.01 ; n=8-16 /$ group).

Next, we compared retigabine and SF0034 in the cornealkindled seizure model, which has been used to identify anticonvulsant drugs for the treatment of human partial epilepsy (Racine et al., 1972; Matagne and Klitgaard, 1998). In this model, tetracaine hydrochloride $(0.5 \%$ solution $)$ is applied to each eye and the optic nerve is stimulated through corneal electrodes $(8 \mathrm{~mA}, 60 \mathrm{~Hz}, 3 \mathrm{~s}$, twice a day). The stimulation protocol is continued until the mouse achieves 5 consecutive seizure stages, including mouth and facial clonus (Stage I), head nodding (Stage II), forelimb clonus (Stage III), rearing (Stage IV), and repeated rearing and falling (Stage V), when it is considered fully kindled. In this model, SF0034 was also significantly more potent than retigabine in preventing seizures (Fig. $7 B$; $\mathrm{SF} 0034, \mathrm{ED}_{50}: 3.96 \pm 1.55 \mathrm{mg} / \mathrm{kg}$; retigabine, $\mathrm{ED}_{50}$ : $43.13 \pm 22.26 \mathrm{mg} / \mathrm{kg}, p<0.01 ; n=8-16 /$ group). Together, our results show that the anticonvulsant $\mathrm{ED}_{50}$ of $\mathrm{SF} 0034$ is significantly lower compared with retigabine in both generalized and partial animal models of seizures, suggesting that lower doses of 
A

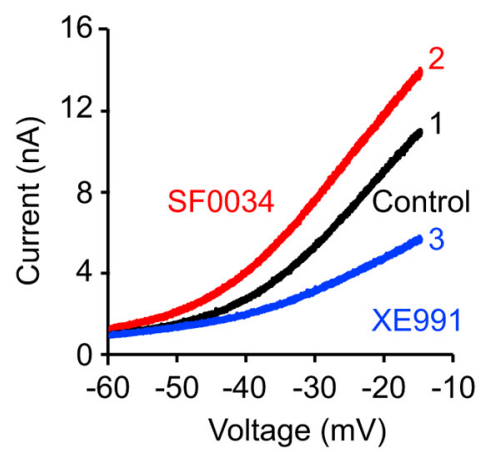

D

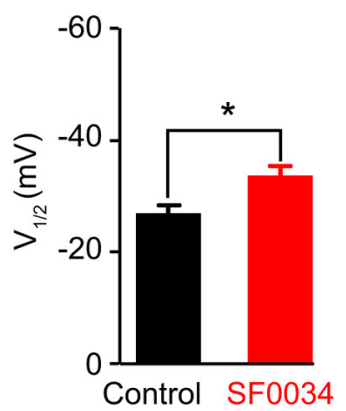

B

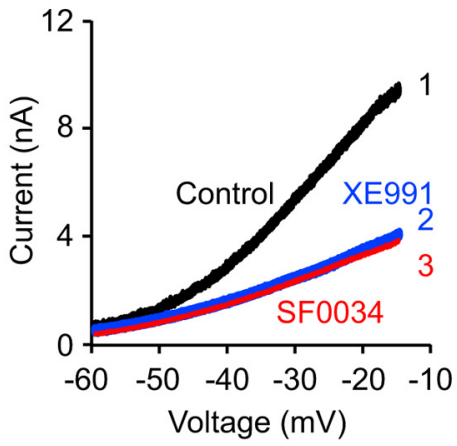

E

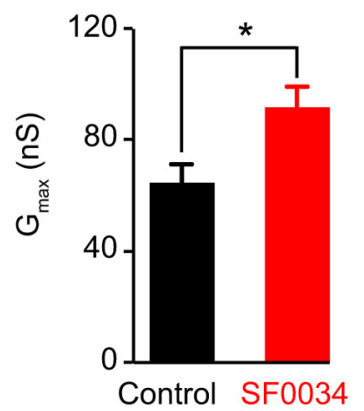

C

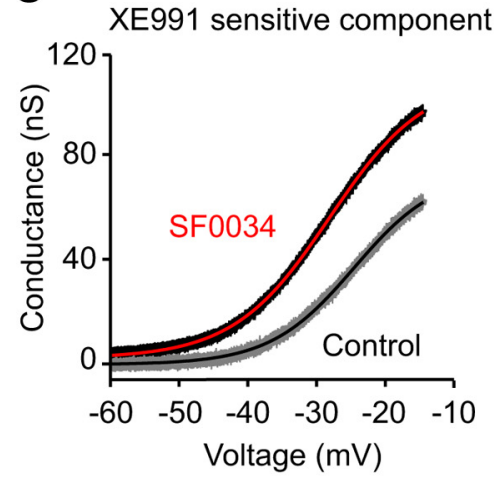

F

Control

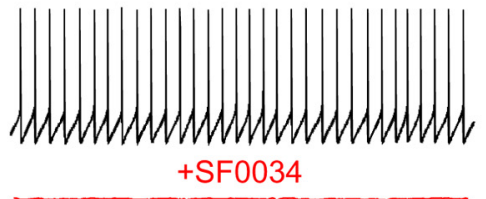

+XE991

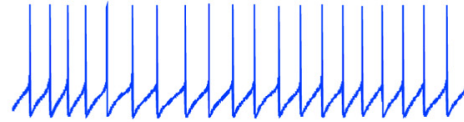

Figure 6. Potentiation of KCNQ channels by SF0034 in DCN principal neurons. A, Representative traces of outward current elicited by a slow voltage ramp (8 $\mathrm{mV} / \mathrm{s})$-mediated activation of KCNQ channels; control response (black trace) is potentiated by bath application of $10 \mu \mathrm{m}$ SF0034 (red trace) that is partially blocked by $10 \mu \mathrm{m}$ XE991 (blue trace); 1, 2, and 3 represents the order of the different pharmacological manipulations. B, Bath application of $10 \mu \mathrm{m}$ SF0034 (red trace) was unable to potentiate control response (black trace) that was partially blocked by bath application of $10 \mu \mathrm{M}$ XE991 (blue trace). 1, 2, and 3 represents the order of the different pharmacological manipulations. C, Representative $G-V$ relationship of XE991-sensitive current (digitally subtracted) in the absence (gray trace) or presence (black trace) of $10 \mu \mathrm{m}$ SF0034. Red and black lines represent Boltzmann fits. $\boldsymbol{D}-\boldsymbol{E}$, Summary of Boltzmann fit parameters $V_{1 / 2}$ and $G_{\max }$. ${ }$, Representative current-clamp traces exhibiting cessation of spontaneous firing of fusiform neurons (black trace) by bath application of $10 \mu \mathrm{MSF} 0034$ (red trace) and its recovery upon subsequent bath application of $10 \mu \mathrm{M}$ XE991 (blue trace). Error bars indicate \pm SEM. ${ }^{*} p<0.05$.

SF0034 may be capable of preventing various types of seizures in humans.

Apart from efficacy, another crucial factor for assessing a potentially therapeutic compound is its degree of toxicity. To compare the toxicity associated with SF0034 and retigabine, we assessed the $\mathrm{TD}_{50}$, the dose of retigabine or SF0034 required to produce toxicity in $50 \%$ of the tested animals, in two different animal models of toxicity. In the positional sense/stance/gait toxicity test, either one hind leg is gently lowered over the edge of a table, whereupon the rat experiencing neurological deficit will fail to lift its leg quickly back to a normal position, or neurotoxicity is indicated by a circular or zigzag gait, ataxia, abnormal spread of the legs, abnormal posture, tremor hyperactivity, lack of exploratory behavior, somnolence, stupor, or catalepsy (Stables and Kupferberg, 1997). In this test, SF0034 had higher $\mathrm{TD}_{50}$, suggesting that it is significantly less toxic than retigabine (Fig. $7 C$; SF0034, $\mathrm{TD}_{50}: 150.32 \pm 50.34 \mathrm{mg} / \mathrm{kg}$; retigabine, $\mathrm{TD}_{50}$ : $94.34 \pm 23.43 \mathrm{mg} / \mathrm{kg}, p<0.05 ; n=8-16 /$ group). In the rotarod toxicity test, which screens for drug-induced toxicity that disables mice from maintaining their equilibrium on a rotating rod (Dunham and Miya, 1957), SF0034 and retigabine showed similar $\mathrm{TD}_{50}$ (Fig. 7D; SF0034, $\mathrm{TD}_{50}: 43.31 \pm 22.26 \mathrm{mg} / \mathrm{kg}$; retigabine, $\mathrm{TD}_{50}: 62.45 \pm 30.80 \mathrm{mg} / \mathrm{kg}, p>0.05 ; n=8-16 /$ group $)$. Together, these results suggest that SF0034 is more potent in its anticonvulsant activity and overall less toxic compared with retigabine; therefore, SF0034 has a significantly improved therapeutic index $\left(\mathrm{TD}_{50} / \mathrm{ED}_{50}\right)$. We conclude that SF0034 represents a novel compound with improved safety and efficacy profile compared with the FDA-approved anti-epileptic drug Potiga (the US trade name for retigabine).

\section{SF0034 prevents the development of tinnitus in mice}

To assess the generality of SF0034 in preventing pathological symptoms in hyperexcitability-related disorders, we tested the effect of SF0034 in an animal model of tinnitus. The induction of tinnitus is associated with hyperexcitability in the auditory brainstem (Brozoski et al., 2002; Kaltenbach et al., 2004; Kaltenbach et al., 2005). Importantly, recent studies have shown that reduction of KCNQ2/3 channel activity in the DCN is associated with DCN hyperexcitability and the induction of tinnitus (Li et al., 2013). Consistent with this notion, administration of retigabine after noise exposure (tinnitus-inducing stimulus) prevents the development of tinnitus in mice (Li et al., 2013). To determine whether administration of SF0034 prevents the induction of tinnitus, we examined the effect of SF0034 in a mouse model of noise-induced tinnitus (Turner et al., 2006; Li et al., 2013). According to this behavioral paradigm, control mice exhibit normal startle reflex in response to a startle pulse, which is embedded in a constant background sound that does not elicit startle (Fig. 8A, $a 1$ and $a 3$, gray trace). In agreement with previous studies, the insertion of a silent gap in the constant background sound that precedes the startle sound inhibits the magnitude of the startle reflex (Fig. $8 \mathrm{~A}$, $a 2$ and $a 3$, red trace). However, after exposure to loud sound (16 $\mathrm{kHz}$ at $116 \mathrm{~dB}$ SPL centered at $1 \mathrm{kHz}$ bandwidth for $45 \mathrm{~min}$ ), 
A

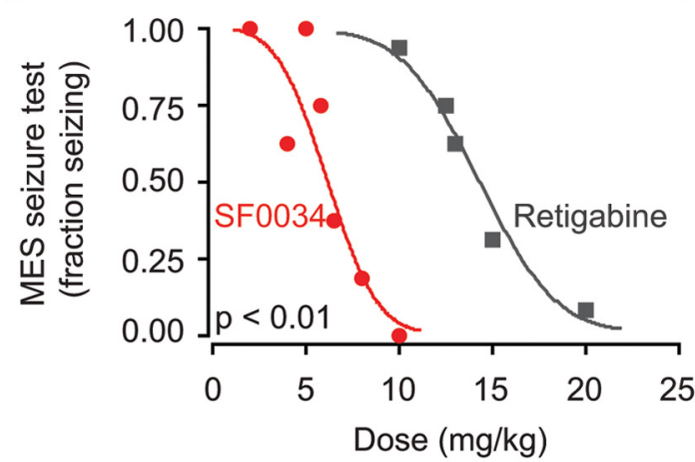

C

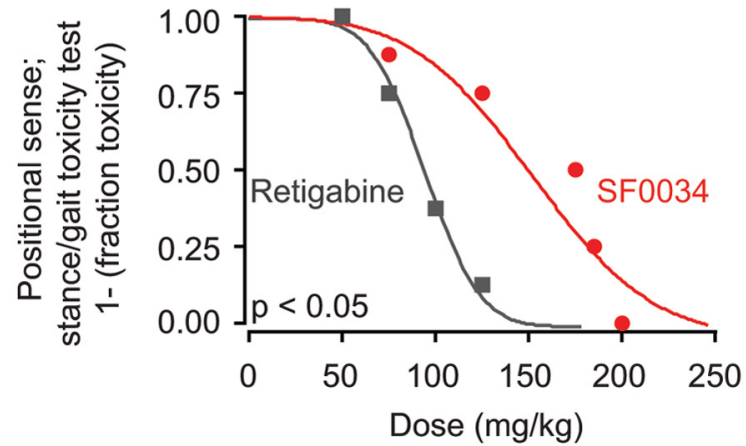

D
B

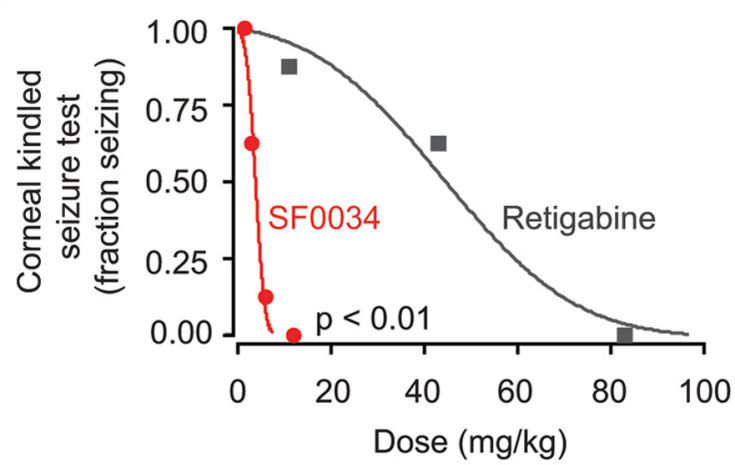

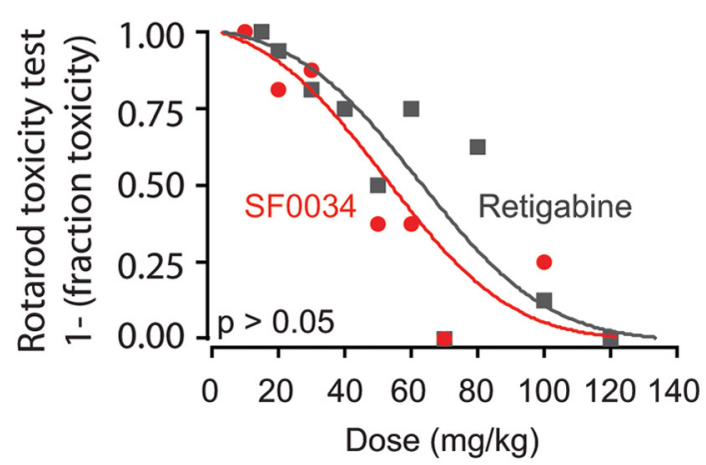

Figure 7. SF0034 is more potent anticonvulsant than retigabine and is less toxic than retigabine. $A, B$, Comparison of dose-response curves for $\mathrm{ED}_{50}$ Calculation ( $x$-axis: dose $(\mathrm{mg} / \mathrm{kg}) ; y$-axis: fraction seizure) for SF0034 (red) and retigabine (gray) in an MES seizure mouse model $(\boldsymbol{A})$ and a corneal-kindled seizure mouse model (B). $\boldsymbol{C}, \boldsymbol{D}$, Comparison of dose-response curves $(X$-axis: dose for $\mathrm{TD}_{50}$ calculation (mg/kg); $y$-axis: 1-fraction toxicity) for SF0034 (red) and retigabine (gray) in the rat positional sense/stance/gait toxicity model (C) and the mice rotarod toxicity model (D).

when an animal develops tinnitus in a frequency that is matched by the background sound, this animal is unable to detect the silent gap due to partial masking of the gap perception by tinnitus. This "masking" effect results in less inhibition of the startle reflex in tinnitus mice and therefore provides a metric for assessing the behavioral evidence of tinnitus (Fig. $8 A, a 4$, gray and red traces).

To evaluate the efficacy of SF0034 in preventing the development of tinnitus, SF0034 (10 mg/kg, i.p.) was administered to noise-exposed animals $30 \mathrm{~min}$ after noise exposure, followed by injections twice per day for $5 \mathrm{~d}$ as described previously (Li et al., 2013). Compared with noise-exposed mice administered with vehicle (methylcellulose, $0.5 \%$ ), injection of SF0034 reduced the percentage of noise-exposed mice that developed tinnitus (Fig. $8 B$; noise-exposed + vehicle: $52.9 \%, 9$ of 17 ; noise exposed + SF0034: $17.6 \%, 3$ of 17, $p<0.05)$. Moreover, administration of vehicle or SF0034 did not affect the percentage of animals that exhibited behavioral evidence of tinnitus in sham (not noiseexposed) groups, suggesting that that the effect of SF0034 is specific to noise-induced tinnitus (Fig. $8 B$; sham + vehicle: $30.0 \%$, $n=3$ of 10 ; sham + SF0034: $30.0 \%, 3$ of $10, p>0.05)$.

SF0034-mediated changes in temporal processing deficits or hearing thresholds may confound the interpretation of gap detection paradigm used for tinnitus screening. To evaluate the potential effects of SF0034 on sensorimotor gating and hearing thresholds, we tested the effect of SF0034 on PPIs and ABRs to sound. In the PPI paradigm, when an auditory stimulus that does not cause startle precedes a startle pulse closely in time, animals with normal sensorimotor gating exhibit a reduced reflex to the same startle pulse (Fig. 8C). SF0034 did not have any effect on PPI, suggesting that SF0034 does not alter the ability of mice to inhibit startle responses (Fig. 8D). To test the effect of SF0034 on hearing thresholds, we measured ABRs, which reflect the synchronous activity of auditory brainstem nuclei in response to sound arising from the auditory nerve (wave I) to the inferior colliculus (wave V) (Fig. 8E; waves II-IV represent the activity of various auditory brainstem nuclei). SF0034 did not have any effect on ABR thresholds, suggesting that it does not alter hearing thresholds (Fig. 8F). We conclude that SF0034 prevents the development of tinnitus in noise-exposed animal model of tinnitus without affecting temporal processing or hearing thresholds.

\section{Discussion}

An estimated 65 million people worldwide currently live with epilepsy (Thurman et al., 2011), of which 25-40\% are refractory to available treatments (Eadie, 2012). Drugs with novel mechanisms of action have been long sought; one of the two such drugs recently approved by FDA is the KCNQ2-5 activator retigabine (Gunthorpe et al., 2012). However, this drug is saddled with a number of pharmacological liabilities that cause significant side effects at therapeutic doses. Namely, Potiga has several side effects, including urinary retention, dizziness, sleepiness, vertigo, tremor, confusion, psychiatric problems, vision changes, and arrhythmia. Over the last year, the FDA released a safety alert reporting that Potiga can cause blue skin coloration and pigment changes in the retina and severely restricted its use to those patients who have responded inadequately to several alternative treatments. Therefore, the need for a more specific, more potent, and less toxic KCNQ2/3 activator is essential for the development of therapeutic drugs for hyperexcitability-related disorders such as epilepsy and tinnitus. To mitigate the toxicity associated with retigabine, we used the strategic incorporation of a fluorine sub- 
stituent in retigabine. We developed SF0034, which is more potent and more KCNQ2/3 specific than retigabine.

Retigabine, the parent compound of SF0034, interacts with multiple conserved residues in both the S5 inner loop and S6 domains of KCNQ2-5 channels (Schenzer et al., 2005; Wuttke et al., 2005; Lange et al., 2009). Namely, W265, L272, L314, and Leu-338 (KCNQ3 numbering) and G301/G340 (KCNQ2/KCNQ3 numbering) are critical residues for the gating effects of retigabine. These amino acids are found in all retigabine-sensitive subunits and, therefore, the subtle differences in the spatial arrangement of these residues in the 3D structure may determine the differential retigabine sensitivity among the different KCNQ2-5 subunits (Lange et al., 2009). Because one of the proposed critical interactions of retigabine with KCNQ2-5 channels is through the aniline ring of retigabine and G301 (Wuttke et al., 2005), to improve the potency and selectivity of retigabine, we synthesized retigabine analogs bearing one or two fluorine atoms on the aniline ring. This strategy was based on the assumption that the position of fluoro- substitution on the ring would differentially modulate the interaction between retigabine and G301. Although our results do not test directly our assumption, and therefore additional studies are needed for identifying the underlying mechanism by which SF0034 is more potent and specific than retigabine, our approach generated a unique retigabine analog with improved potency and selectivity. We therefore propose that SF0034 could act as a foundation for developing new compounds with even higher potency and selectivity among KCNQ channels.

\section{New KCNQ channel activators as potential therapeutics for} hyperexcitability-related disorders Due to its more potent effect on KCNQ2/3 channels (Figs. 2, 5, 6), SF0034 is more effective at a lower dose than retigabine in preventing seizures (Fig. 7). In addition, SF0034 displays reduced affinity for the channels associated with toxic side effects, such as KCNQ4 and KCNQ5 (Fig. 4). The lack of effect of SF0034 on KCNQ4 channels at near resting membrane potentials is unique among KCNQ channel activators. KCNQ4 is the primary potassium channel in the smooth muscle of the bladder, where it serves to regulate contractility (Jentsch, 2000; Greenwood and Ohya, 2009). Activation of KCNQ4 leads to membrane hyperpolarization and a re-
A

a1

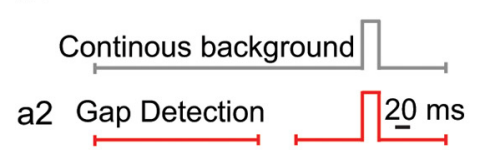

a3

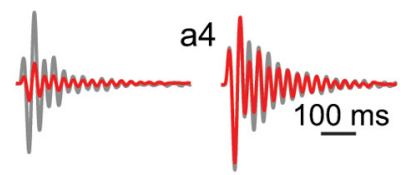

Control

Tinnitus

B

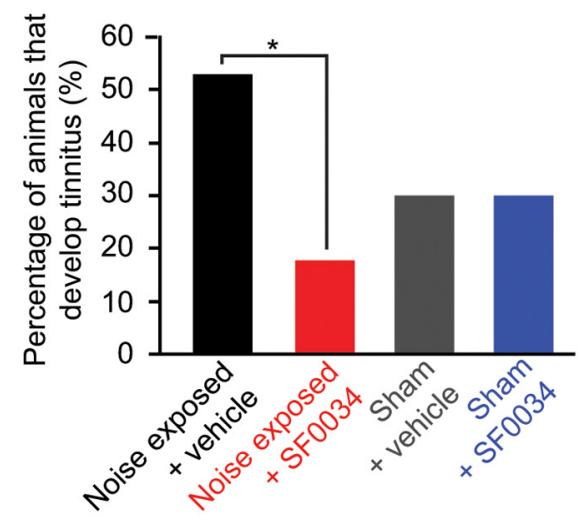

C

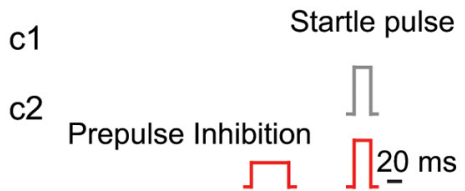

c3

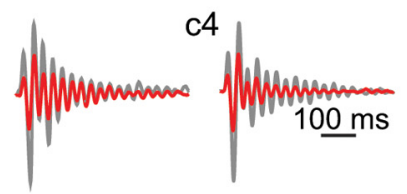

Control

Tinnitus

E

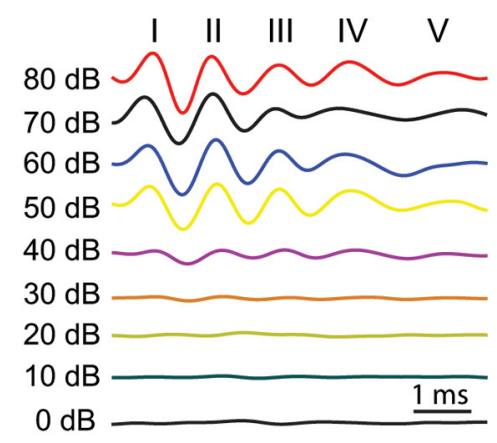

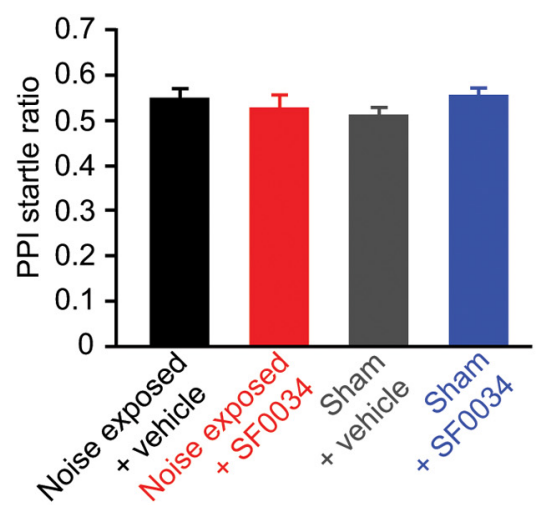

$\mathbf{F}$

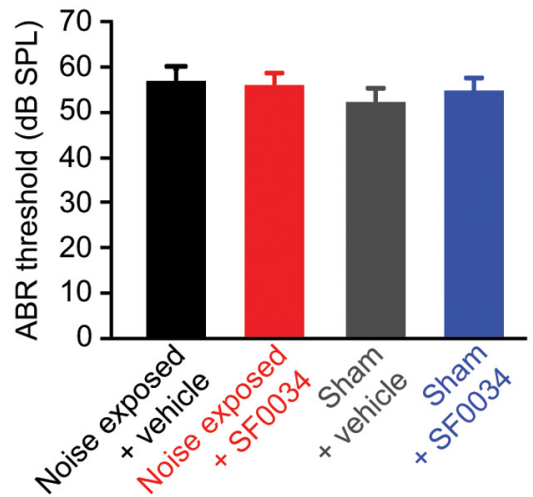

Figure 8. SF0034 prevents the development of tinnitus. A, Diagram illustrating the gap detection protocol. Gray trace (a1): a startle stimulus preceded by a constant background sound; red trace (a2): a startle stimulus preceded by a constant background sound containing a brief gap. a 3 and a 4 are representative raw traces of startle responses in control (a3) and tinnitus (a4) animals elicited by the gap detection protocol. Introduction of a brief gap in the constant background sound results in a robust inhibition of startle reflex in a control mouse (a3, red) and thus lower gap-startle ratios (response to gap and startle stimulus/response to startle stimulus alone). However, when noise-exposed animals experience tinnitus at or near the frequency of the background sound, they have difficulty in detecting the gap, resulting in less inhibition of startle reflex in response to startle stimulus (a4, red) and higher gap-startle ratios. $\boldsymbol{B}$, Percentage of mice that develop tinnitus (noise exposed $+0.5 \%$ methycellulose, $n=17$; noiseexposed + SF0034, $n=17$; Sham $+0.5 \%$ methycellulose, $n=10$; sham + SF0034, $n=10)$. C, Diagram illustrating the PPI protocol. Representative raw startle responses elicited by a startle stimulus $(\mathrm{C} 1)$ or by a startle stimulus preceded by a brief nonstartling stimulus (C2) in control (C3) and tinnitus (C4) animals. D, Summary of PPI startle ratio (response to prepulse and startle stimulus/response to startle stimulus alone) for high-frequency sounds ( $20-32 \mathrm{kHz}$ ) (PPI startle ratio, noise exposed $+0.5 \%$ methycellulose, $n=17$; noise-exposed + SF0034, $n=17$; sham $+0.5 \%$ methycellulose, $n=10$; sham + SF0034, $n=10$ ). $\boldsymbol{E}$, Representative raw traces of ABR in response to $20 \mathrm{kHz}$ tone presented at different intensities (dB). I-V represent the different waves of the ABR. $\boldsymbol{F}$, Summary of ABR thresholds for high-frequency sounds $(20-32 \mathrm{kHz}$ ) (noise exposed $+0.5 \%$ methycellulose, $n=17$; noise-exposed + SF0034, $n=17$; Sham $+0.5 \%$ methycellulose, $n=10$; sham + SF0034, $n=10) .{ }^{*} p<0.05$. Error bars indicate \pm SEM. ${ }^{*} p<0.05$. 
sultant loss of contractile function, a possible etiology for the urinary retention side effect of retigabine. Moreover, a form of dominant deafness arises from impaired function of KCNQ4 (Kharkovets et al., 2000), so nonspecific opening of these channels may have unwanted side effects on hearing. In addition to expression in the CNS, KCNQ4 and KCNQ5 are also found in skeletal muscle (Jentsch, 2000; Iannotti et al., 2010; Iannotti et al., 2013). Given the lack of effect of SF0034 on either KCNQ4 or KCNQ5 channels, SF0034 is not expected to have any unwanted effects in skeletal muscle. In conclusion, we propose that the combination of increased potency and selectivity of SF0034 may overcome the toxicity associated with retigabine, which has resulted in severe restrictions on its use.

Although the mechanism by which retigabine generates toxicity to the skin and retina remains unknown, these toxicities occur in organs that are exposed to light and UV radiation. Elevated exposure to UV radiation by causing photodegradation and oxidation of retigabine's aniline ring may lead to the formation of highly colored compounds in the skin and eyes. Such formation may provide a mechanism for the observed toxicities. The incorporation of an electron-withdrawing fluorine substituent on the aniline ring of retigabine is expected to reduce the oxidation potential, thus making SF0034 potentially less prone to photodegradation and potentially less toxic to the eye and to the skin.

SF0034 may also be a potential clinical candidate for patients with KCNQ2 encephalopathy. KCNQ2 potassium channels have recently emerged as crucial regulators of neuronal excitability in the neonatal brain. Mutations in the KCNQ2 gene lead to multiple severe pediatric epilepsy disorders including neonatal and infantile epileptic encephalopathy (Weckhuysen et al., 2012; Kato et al., 2013; Weckhuysen et al., 2013; Numis et al., 2014). Because KCNQ2 encephalopathy affects only one copy of the KCNQ2 gene (Kato et al., 2013; Miceli et al., 2013), it has been suggested that retigabine administration, by activating the nonmutated KCNQ2/3 channels, may have beneficial effects in KCNQ2 encephalopathy patients. We propose that SF0034, which minimizes the off-target toxicity associated with retigabine, may be a more appropriate treatment for patients with KCNQ2 encephalopathy, particularly children.

Because noise-induced reduction in KCNQ2/3 channels is associated with the induction of tinnitus and retigabine prevents the development of tinnitus in a mouse model (Li et al., 2013), we propose that SF0034 is a potential clinical candidate for the treatment of tinnitus. Tinnitus is the sound perception in the absence of an acoustic event and is experienced by up to $15 \%$ of the general population (Shargorodsky et al., 2010). Of the 40 million in the United States with tinnitus, $\sim 10$ million seek medical attention (Seidman and Jacobson, 1996) and 2.5 million of these are considered disabled by tinnitus due to its persistence and intensity. Despite an even higher prevalence of tinnitus in recent demographics, including recent war veterans and the increasing aging population (Yankaskas, 2013), there is no generally accepted treatment or cure. Although tinnitus can be incapacitating for many sufferers, in most cases, it is not life threatening and therefore it would not be clinically appropriate to use retigabine with such an extensive toxicity profile. For patients with incapacitating tinnitus, the acceptable degree of toxicity/side effects must be considered relative to the degree of symptoms. Many patients with incapacitating tinnitus have been treated off-label with carbamazepine (which has a risk of cardiac arrhythmia, double vision, and aplastic anemia) and tricyclic antidepressants such as nortriptyline or amitryptiline (with side effects including seda- tion, blurred vision, mania, and arrhythmia). Invasive treatments such as auditory cortical stimulation (Friedland et al., 2007), which involve surgical implantation of an epidural electrode, have been explored for severe tinnitus. In light of the risks associated with these alternative treatments, we propose that SF0034, which shows an improved efficacy and safety profile, has the potential to be an effective clinical option for patients with mild or severe (incapacitating) tinnitus.

\section{References}

Bean BP (2007) The action potential in mammalian central neurons. Nat Rev Neurosci 8:451-465. CrossRef Medline

Brown DA, Adams PR (1980) Muscarinic suppression of a novel voltagesensitive $\mathrm{K}+$ current in a vertebrate neurone. Nature 283:673-676. CrossRef Medline

Brozoski TJ, Bauer CA, Caspary DM (2002) Elevated fusiform cell activity in the dorsal cochlear nucleus of chinchillas with psychophysical evidence of tinnitus. J Neurosci 22:2383-2390. Medline

Dunham NW, Miya TS (1957) A note on a simple apparatus for detecting neurological deficit in rats and mice. J Am Pharm Assoc Am Pharm Assoc (Baltim) 46:208-209. Medline

Eadie MJ (2012) Shortcomings in the current treatment of epilepsy. Expert Rev Neurother 12:1419-1427. CrossRef Medline

Friedland DR, Gaggl W, Runge-Samuelson C, Ulmer JL, Kopell BH (2007) Feasibility of auditory cortical stimulation for the treatment of tinnitus. Otol Neurotol 28:1005-1012. CrossRef Medline

Greenwood IA, Ohya S (2009) New tricks for old dogs: KCNQ expression and role in smooth muscle. Br J Pharmacol 156:1196-1203. CrossRef Medline

Gunthorpe MJ, Large CH, Sankar R (2012) The mechanism of action of retigabine (ezogabine), a first-in-class $\mathrm{K}+$ channel opener for the treatment of epilepsy. Epilepsia 53:412-424. CrossRef Medline

Hernandez CC, Falkenburger B, Shapiro MS (2009) Affinity for phosphatidylinositol 4,5-bisphosphate determines muscarinic agonist sensitivity of Kv7 K+ channels. J Gen Physiol 134:437-448. CrossRef Medline

Iannotti FA, Panza E, Barrese V, Viggiano D, Soldovieri MV, Taglialatela M (2010) Expression, localization, and pharmacological role of Kv7 potassium channels in skeletal muscle proliferation, differentiation, and survival after myotoxic insults. J Pharmacol Exp Ther 332:811-820. CrossRef Medline

Iannotti FA, Barrese V, Formisano L, Miceli F, Taglialatela M (2013) Specification of skeletal muscle differentiation by repressor element-1 silencing transcription factor (REST)-regulated Kv7.4 potassium channels. Mol Biol Cell 24:274-284. CrossRef Medline

Jankovic S, Ilickovic I (2013) The preclinical discovery and development of ezogabine for the treatment of epilepsy. Expert Opin Drug Discov 8:1429-1437. CrossRef Medline

Jensen HS, Callø K, Jespersen T, Jensen BS, Olesen SP (2005) The KCNQ5 potassium channel from mouse: a broadly expressed M-current like potassium channel modulated by zinc, $\mathrm{pH}$, and volume changes. Brain Res Mol Brain Res 139:52-62. CrossRef Medline

Jentsch TJ (2000) Neuronal KCNQ potassium channels: physiology and role in disease. Nat Rev Neurosci 1:21-30. CrossRef Medline

Kaltenbach JA, Zacharek MA, Zhang J, Frederick S (2004) Activity in the dorsal cochlear nucleus of hamsters previously tested for tinnitus following intense tone exposure. Neurosci Lett 355:121-125. CrossRef Medline

Kaltenbach JA, Zhang J, Finlayson P (2005) Tinnitus as a plastic phenomenon and its possible neural underpinnings in the dorsal cochlear nucleus. Hear Res 206:200-226. CrossRef Medline

Kato M, Yamagata T, Kubota M, Arai H, Yamashita S, Nakagawa T, Fujii T, Sugai K, Imai K, Uster T, Chitayat D, Weiss S, Kashii H, Kusano R, Matsumoto A, Nakamura K, Oyazato Y, Maeno M, Nishiyama K, Kodera H, Nakashima M, Tsurusaki Y, Miyake N, Saito K, Hayasaka K, Matsumoto N, Saitsu H (2013) Clinical spectrum of early onset epileptic encephalopathies caused by KCNQ2 mutation. Epilepsia 54:1282-1287. CrossRef Medline

Kharkovets T, Hardelin JP, Safieddine S, Schweizer M, El-Amraoui A, Petit C, Jentsch TJ (2000) KCNQ4, a K+ channel mutated in a form of dominant deafness, is expressed in the inner ear and the central auditory pathway. Proc Natl Acad Sci U S A 97:4333-4338. CrossRef Medline

Lange W, Geissendörfer J, Schenzer A, Grötzinger J, Seebohm G, Friedrich T, 
Schwake M (2009) Refinement of the binding site and mode of action of the anticonvulsant Retigabine on KCNQ K+ channels. Mol Pharmacol 75:272-280. CrossRef Medline

Leao RM, Li S, Doiron B, Tzounopoulos T (2012) Diverse levels of an inwardly rectifying potassium conductance generate heterogeneous neuronal behavior in a population of dorsal cochlear nucleus pyramidal neurons. J Neurophysiol 107:3008-3019. CrossRef Medline

Li S, Choi V, Tzounopoulos T (2013) Pathogenic plasticity of Kv7.2/3 channel activity is essential for the induction of tinnitus. Proc Natl Acad Sci U S A 110:9980-9985. CrossRef Medline

Li Y, Gamper N, Hilgemann DW, Shapiro MS (2005) Regulation of Kv7 (KCNQ) $\mathrm{K}+$ channel open probability by phosphatidylinositol 4,5bisphosphate. J Neurosci 25:9825-9835. CrossRef Medline

Matagne A, Klitgaard H (1998) Validation of corneally kindled mice: a sensitive screening model for partial epilepsy in man. Epilepsy Res 31:59-71. CrossRef Medline

Miceli F, Soldovieri MV, Ambrosino P, Barrese V, Migliore M, Cilio MR, Taglialatela M (2013) Genotype-phenotype correlations in neonatal epilepsies caused by mutations in the voltage sensor of $\mathrm{K}(\mathrm{v}) 7.2$ potassium channel subunits. Proc Natl Acad Sci U S A 110:4386-4391. CrossRef Medline

Numis AL, Angriman M, Sullivan JE, Lewis AJ, Striano P, Nabbout R, Cilio MR (2014) KCNQ2 encephalopathy: delineation of the electroclinical phenotype and treatment response. Neurology 82:368-370. CrossRef Medline

Racine R, Okujava V, Chipashvili S (1972) Modification of seizure activity by electrical stimulation. 3. Mechanisms. Electroenceph Clin Neurophysiol 32:295-299. CrossRef Medline

Schenzer A, Friedrich T, Pusch M, Saftig P, Jentsch TJ, Grötzinger J, Schwake M (2005) Molecular determinants of KCNQ (Kv7) K+ channel sensitivity to the anticonvulsant retigabine. J Neurosci 25:5051-5060. CrossRef Medline

Schroeder BC, Hechenberger M, Weinreich F, Kubisch C, Jentsch TJ (2000) KCNQ5, a novel potassium channel broadly expressed in brain, mediates M-type currents. J Biol Chem 275:24089-24095. CrossRef Medline

Seidman MD, Jacobson GP (1996) Update on tinnitus. Otolaryngol Clin North Am 29:455-465. Medline

Shargorodsky J, Curhan GC, Farwell WR (2010) Prevalence and characteristics of tinnitus among US adults. Am J Med 123:711-718. CrossRef Medline

Singh NA, Charlier C, Stauffer D, DuPont BR, Leach RJ, Melis R, Ronen GM, Bjerre I, Quattlebaum T, Murphy JV, McHarg ML, Gagnon D, Rosales TO, Peiffer A, Anderson VE, Leppert M (1998) A novel potassium channel gene, KCNQ2, is mutated in an inherited epilepsy of newborns. Nat Genet 18:25-29. CrossRef Medline

Singh NA, Westenskow P, Charlier C, Pappas C, Leslie J, Dillon J, Anderson VE, Sanguinetti MC, Leppert MF; BFNC Physician Consortium (2003) KCNQ2 and KCNQ3 potassium channel genes in benign familial neonatal convulsions: expansion of the functional and mutation spectrum. Brain 126:2726-2737. CrossRef Medline

Soh H, Tzingounis AV (2010) The specific slow afterhyperpolarization inhibitor UCL2077 is a subtype-selective blocker of the epilepsy associated KCNQ channels. Mol Pharmacol 78:1088-1095. CrossRef Medline

Soh H, Pant R, LoTurco JJ, Tzingounis AV (2014) Conditional deletions of epilepsy-associated KCNQ2 and KCNQ3 channels from cerebral cortex cause differential effects on neuronal excitability. J Neurosci 34:53115321. CrossRef Medline

Stables JP, Kupferberg HJ (1997) The NIH Anticonvulsant Drug Development (ADD) Program: preclinical anticonvulsant screening project. In: Molecular and cellular targets for anti-epileptic drugs (Avanzini G, Tanganelli P, Avoli M, eds), pp 191-198. New Barnet, UK: John Libbey.

Tatulian L, Delmas P, Abogadie FC, Brown DA (2001) Activation of expressed KCNQ potassium currents and native neuronal M-type potassium currents by the anti-convulsant drug retigabine. J Neurosci 21: 5535-5545. Medline

Thurman DJ, Beghi E, Begley CE, Berg AT, Buchhalter JR, Ding D, Hesdorffer DC, Hauser WA, Kazis L, Kobau R, Kroner B, Labiner D, Liow K, Logroscino G, Medina MT, Newton CR, Parko K, Paschal A, Preux PM, Sander JW, et al. (2011) Standards for epidemiologic studies and surveillance of epilepsy. Epilepsia 52:2-26. CrossRef Medline

Turner JG, Brozoski TJ, Bauer CA, Parrish JL, Myers K, Hughes LF, Caspary DM (2006) Gap detection deficits in rats with tinnitus: a potential novel screening tool. Behav Neurosci 120:188-195. CrossRef Medline

Tzounopoulos T, Kim Y, Oertel D, Trussell LO (2004) Cell-specific, spike timing-dependent plasticities in the dorsal cochlear nucleus. Nat Neurosci 7:719-725. CrossRef Medline

Wang HS, Pan Z, Shi W, Brown BS, Wymore RS, Cohen IS, Dixon JE, McKinnon D (1998) KCNQ2 and KCNQ3 potassium channel subunits: molecular correlates of the M-channel. Science 282:1890-1893. CrossRef Medline

Weckhuysen S, Mandelstam S, Suls A, Audenaert D, Deconinck T, Claes LR, Deprez L, Smets K, Hristova D, Yordanova I, Jordanova A, Ceulemans B, Jansen A, Hasaerts D, Roelens F, Lagae L, Yendle S, Stanley T, Heron SE, Mulley JC, et al. (2012) KCNQ2 encephalopathy: emerging phenotype of a neonatal epileptic encephalopathy. Ann Neurol 71:15-25. CrossRef Medline

Weckhuysen S, Ivanovic V, Hendrickx R, Van Coster R, Hjalgrim H, Moller RS, Gronborg S, Schoonjans AS, Ceulemans B, Heavin SB, Eltze C, Horvath R, Casara G, Pisano T, Giordano L, Rostasy K, Haberlandt E, Albrecht B, Bevot A, Benkel I, et al. (2013) Extending the KCNQ2 encephalopathy spectrum: clinical and neuroimaging findings in $17 \mathrm{pa}-$ tients. Neurology 81:1697-1703. CrossRef Medline

White HS, Johnson M, Wolf HH, Kupferberg HJ (1995) The early identification of anticonvulsant activity: role of the maximal electroshock and subcutaneous pentylenetetrazol seizure models. Ital J Neurol Sci 16:7377. CrossRef Medline

Wickenden AD, Zou A, Wagoner PK, Jegla T (2001) Characterization of KCNQ5/Q3 potassium channels expressed in mammalian cells. Br J Pharmacol 132:381-384. CrossRef Medline

Woodbury LA, Davenport VD (1952) Design and use of a new electroshock seizure apparatus, and analysis of factors altering seizure threshold and pattern. Archives internationales de pharmacodynamie et de therapie 92: 97-107. Medline

Wuttke TV, Seebohm G, Bail S, Maljevic S, Lerche H (2005) The new anticonvulsant retigabine favors voltage-dependent opening of the Kv7.2 (KCNQ2) channel by binding to its activation gate. Mol Pharmacol 67: 1009-1017. CrossRef Medline

Yankaskas K (2013) Prelude: noise-induced tinnitus and hearing loss in the military. Hear Res 295:3-8. CrossRef Medline 